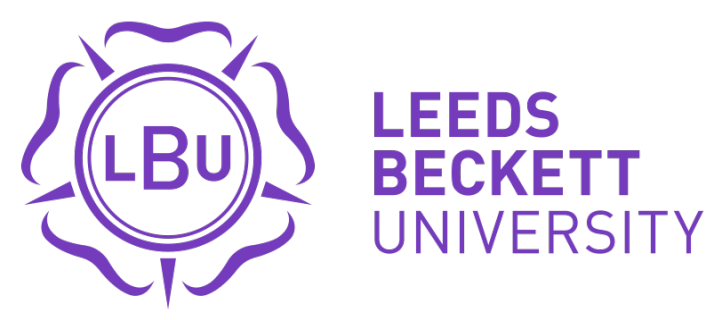

Citation:

Vineet, V and Becerra, V and Bausch, N and Deng, J and Shimjith, SR and Arul, J (2021) LQGI/LTR based Robust Control Technique for a Pressurized Water Nuclear Power Plant. Annals of Nuclear Energy, 154. ISSN 0306-4549 DOI: https://doi.org/10.1016/j.anucene.2020.108105

Link to Leeds Beckett Repository record:

https://eprints.leedsbeckett.ac.uk/id/eprint/7348/

Document Version:

Article (Accepted Version)

Creative Commons: Attribution-Noncommercial-No Derivative Works 4.0

The aim of the Leeds Beckett Repository is to provide open access to our research, as required by funder policies and permitted by publishers and copyright law.

The Leeds Beckett repository holds a wide range of publications, each of which has been checked for copyright and the relevant embargo period has been applied by the Research Services team.

We operate on a standard take-down policy. If you are the author or publisher of an output and you would like it removed from the repository, please contact us and we will investigate on a case-by-case basis.

Each thesis in the repository has been cleared where necessary by the author for third party copyright. If you would like a thesis to be removed from the repository or believe there is an issue with copyright, please contact us on openaccess@leedsbeckett.ac.uk and we will investigate on a case-by-case basis. 


\title{
LQGI/LTR based Robust Control Technique for a Pressurized Water Nuclear Power Plant
}

\author{
Vineet Vajpayee*, Victor Becerra, Nils Bausch, Jiamei Deng, S. R. Shimjith, A. John Arul
}

\begin{abstract}
This work proposes a new hybrid control strategy for a pressurized water type nuclear power plant by integrating linear quadratic integrator (LQI), linear quadratic Gaussian (LQG), and loop transfer recovery (LTR) approaches. The multiinput multi-output nuclear plant model adopted in this work is characterized by 38 state variables. The nonlinear plant model is linearized around steady-state operating conditions to obtain a linear model for the controller design. The proposed LQGI/LTR technique designs state-feedback assisted output control using the estimated states. The control architecture offers robust performance and tracks the reference set-point with zero steadystate error in the presence of uncertainties and disturbances. The effectiveness of the proposed technique is demonstrated by simulations on different subsections of a pressurized water nonlinear nuclear power plant model. The control performance of the proposed technique is further compared with other classical control design schemes. Statistical measures are employed to quantitatively analyse control performance.
\end{abstract}

Index Terms-Optimal control, Robust Control, Hybrid Control, Pressurized Water Reactor, Nuclear Power Plant.

\section{INTRODUCTION}

A nuclear power plant is a complex constrained non-linear dynamical system. Control of a nuclear power plant poses a challenge due to parameter variations caused by fuel burnup, internal reactivity feedbacks, modelling uncertainties, and unknown disturbances. System parameters associated with reactor core, thermal-hydraulics, and reactivity feedbacks differ considerably with operating conditions. Besides, routine load cycles during the load-following mode of operation can significantly degrade performance due to a broad range of power variations. Uncertainties in the actuators signals and noisy sensor measurements add further challenges to the control design problem. Consequently, traditional controllers struggle to deliver good performance. The controller must be able to respond steadily to fast variations in the set-point without compromising the performance. Thus, it is of prime importance to improve the existing control techniques for the

* Corresponding author

Vineet Vajpayee (vineet.vajpayee@port.ac.uk), Victor Becerra (victor.becerra@port.ac.uk), and Nils Bausch (nils.bausch@port.ac.uk) are with School of Energy and Electronic Engineering, University of Portsmouth, Portsmouth, PO1 3DJ, United Kingdom.

Jiamei Deng (j.deng@leedsbeckett.ac.uk) is with School of Built Environment, Engineering, and Computing, Leeds Beckett University, Leeds, LS6 3QS, United Kingdom.

S. R. Shimjith (srshim@barc.gov.in) is with Reactor Control System Design Section, Bhabha Atomic Research Centre, Mumbai, 400 085, India and Homi Bhabha National Institute, Mumbai, 400 094, India.

A. John Arul (arul@igcar.gov.in) is with Probabilistic Safety, Reactor Shielding and Nuclear Data Section, Indira Gandhi Centre for Atomic Research, Kalpakkam, 603 102, India. enhancement of safety and operability of a nuclear power plant.

In the last few decades, various robust control design techniques such as $\mathcal{H}_{\infty}$ control [1]-[5], model predictive control (MPC) [6]-[14], sliding mode control (SMC) [15][20], and other soft-computing-based controls [21]-[30] have been proposed to deal with uncertainties in a nuclear power plant. An $\mathcal{H}_{\infty}$-based control approach was first proposed by Suzuki et al. [1] to obtain better robustness over the classical control schemes for reactor core power control. Chi et al. [2] employed $\mathcal{H}_{\infty}$ control for reactor core xenon control. Emara et al. [3] combined a model-order reduction and linear matrix inequality with an $\mathcal{H}_{\infty}$ approach to design a core power control strategy. Recently, an $\mathcal{H}_{\infty}$-based loop-shaping approach has been proposed by Li et al. [4] to control the nuclear reactor core. Further, Yan et al. [5] proposed an $\mathcal{H}_{\infty}$-based mixed sensitivity method to achieve stable power operations in the presence of external disturbances and uncertainties. However, $\mathcal{H}_{\infty}$-based controllers are optimal only with respect to the prescribed cost function. The controller performance degrades in the presence of non-linear constraints. Moreover, this control approach requires the knowledge and understanding of highlevel mathematics for their successful application.

To deal with system design constraints in an uncertain nuclear power plant system, receding horizon-based robust MPC approaches have been proposed. Etchepareborda et al. [6] proposed an output feedback non-linear receding horizon strategy to control reactor power during known disturbances. $\mathrm{Na}$ et al. [7] incorporated a genetic algorithm optimization with fuzzy MPC for thermal power control of a pressurized water reactor (PWR). Robust MPC has been designed for nonlinear power control and bounding xenon oscillations by Eliasi et al. [8], [9]. The performance of these controllers is reliant on the accurate knowledge of the plant model a priori, which is a stringent requirement in case of aged plants. Recently, subspace-based predictive control approaches have been proposed for the reactor power control of a PWR by Vajpayee et al. [10]-[14].

SMC is another robust control design technique applied to deal with uncertainties in a nuclear power plant system. Ansarifar et al. applied the SMC to the power control of a PWR [15]. Researchers have proposed SMC-based approaches for the power distribution control of a large reactor [16]-[18]. Surjagade et al. [19] integrated SMC with the linear-quadratic approach for the core power control. Recently, Vajpayee et al. [20] proposed an integral SMC-based linear-quadratic tracking design for the control of different loops of a PWR plant. However, the practical implementation of an SMC-based design is 
difficult, as it is susceptible to high-frequency components and sensitive to unmatched uncertainties.

Researchers have assimilated robustness capabilities in the classical proportional-integral-derivative (PID) controllers for reactor power control under parametric variations [21]-[23] Different soft computing-based controllers such as neural network controller [24], intelligent controller [25], emotional controller [26], fuzzy logic controller [27]-[29], and genetic algorithms optimized controller [30] have been proposed to study the load-following problem of nuclear reactors in the presence of disturbances and uncertainties.

A substantial amount of research has been carried out on the application of robust control techniques in nuclear reactors, especially for the core power control. A robust controller often has to spend high control energy to achieve satisfactory performance in an uncertain environment, which may sometimes lead to a saturation of actuators. Pragmatically, a robust control strategy which spends less control energy is desired. This stimulus leads to the advancement of hybrid control strategies by integrating robust control with optimal control which ensures robust performance with lower control efforts [14], [18]-[20], [31]-[33].

Optimal control is a widely applied control design technique that guarantees optimal nominal performance with minimum control efforts. To implement optimal control in actual plants, Edwards et al. [31] proposed state-feedback assisted control (SFAC) to cope with changes of reactor parameters over that of the conventional state-feedback control. In the aforementioned works, many control strategies are developed with the assumption that the complete state information is available. Performance of such controllers is governed by accurate knowledge of the system states. However, in practice, some of the states are not directly available for feedback. For instance, in a reactor core, the concentration of delayed neutron precursors is not directly measurable. Thus, a state estimator is required to estimate the unmeasurable states [15].

Linear-quadratic Gaussian (LQG) is an integrated control design approach involving an optimal linear-quadratic regulator (LQR) for the SFAC and a Kalman filter for the state estimation. However, the incorporation of a Kalman filter weakens the robustness, stability, and performance of the LQR-based design [34]. To address these issues, a loopshaping strategy called loop transfer recovery (LTR) has been proposed by Doyle and Stein [35]. The integrated LQG/LTR approach possesses strong robustness capability in an uncertain environment. The simple structure of the LQG/LTR technique makes it suitable for multi-input multi-output systems. The LQG/LTR controller has been applied to a nuclear power plant deaerator system where it has shown desirable performance in normal operation and also in fault accommodation [36]. Ben-Abdennour et al. [37] proposed an LQG/LTR technique integrated with the SFAC to improve the temperature control of a PWR. A similar approach has been employed by ArabAlibeik et al. to design an LQG/LTR in the SFAC structure [38]. The LQG/LTR design and stability analysis are utilized to design core-power and axial-power control of a PWR by $\mathrm{Li}$ et al. [39]. The authors further integrated the approach with flexibility control for nonlinear core control at a random power level [40]. Lately, Wan et al. [41] proposed an SFAC using a differential lag compensator with the LQG/LTR scheme.

Usually, the LQG/LTR scheme requires designing a large recovery gain to retain robustness, which may result in large control signal variations and may also lead to the saturation of actuators. The LQG/LTR scheme does not guarantee set-point tracking performance, which may be severely compromised in the presence of parametric uncertainties and disturbances. The linear-quadratic integrator (LQI) scheme is proposed to address some of these issues in state-feedback control under the assumption of the availability of states for feedback [42]. LQI includes an integrator in the forward path and acts as an output-feedback controller alongside the state-feedback controller [43], [44]. Motivated by these advantages, a new hybrid control strategy for a PWR-type nuclear power plant is proposed in this paper by integrating the LQI, LQG, and LTR approaches. The state-feedback component from the LQG technique improves the system performance in the presence of process and measurement noise, the output-feedback element from the LQI technique enhances the set-point tracking with zero steady-state error, and the LTR technique increases the robustness in the presence of parametric uncertainties and disturbances. Thus, the hybrid control scheme retains the advantage of these three individual control techniques and overcomes their respective shortcomings. The overall nuclear power plant control scheme possesses a state-estimator with a state-feedback assisted output control to guarantee set-point tracking performance along with improved robustness and enhanced stability margin.

Due to reasons such as commercial restrictions and the understandable conservativeness of the nuclear industry, there is little work reported in the literature on the validation and verification and eventual adoption of advanced control techniques on nuclear power plants [7], [25], [33], [36], [37]. To establish the performance and effectiveness of a control scheme, work published in the early 1990s [36], [37], implemented the nonlinear simulation of the reactor and the controller using the Advanced Continuous Modelling Language (ACSL). There are examples in the literature where the controller $\mathrm{C}++$ code is tested using reactor models such as the DYNCO reactor core calculation code [25]. A MATLABbased controller was tested using a 3-D reactor analysis MASTER code developed in FORTRAN, which can simulate the PWR cores in 3-D geometry [7]. Shaffer et al. experimentally validated their robust controller on the Penn State TRIGA research reactor [33]. In the last decade, many controllers have been developed and tested using MATLAB/Simulink based models of the plant [5], [18], [21]-[23], [28]-[30], [41], [45], which is the approach that has been adopted in this work. In the literature, a simplified model of a PWR, fundamentally designed for studying the load-following mode of operation, is usually employed [2], [15], [24], [40]. The coupling effects among the reactor core, steam generator, pressurizer, turbine-governor, and different piping and plenum are ignored while designing the individual controllers. The dynamics of actuators and sensors are also omitted. It is useful to develop control methods for the whole nuclear power plant system. However, there are very few results for controlling an 
entire nuclear power plant. The proposed LQGI/LTR technique is implemented on different subsections of a simulated nuclear power plant. Specifically, the proposed work addresses the following problems: the load-following mode of operation, the steam generator pressure control, the pressurizer pressure and level control, and turbine speed control. The nonlinear nuclear power plant model employed in this work [46] considers the dynamics of a reactor core, thermal-hydraulics, piping, plenum, steam generator, pressurizer, turbine-governor, sensors, and actuators. The efficacy of the proposed control scheme is tested using various closed-loop simulations in the MATLAB/Simulink environment. The proposed scheme has been further compared with other classical control design techniques. The main contributions of this paper are:

- LQGI/LTR technique is proposed to improve system performance and to enhance set-point tracking in the presence of disturbances and parametric uncertainties.

- Design, validation, and testing of the control strategy are performed for various control loops of a PWR-type nuclear power plant.

- Detailed simulation analysis is done to compare the proposed technique with other classical control schemes.

The remainder of the paper is organized as follows: Section II presents the dynamic non-linear model of a PWRtype nuclear power plant. Section III presents the proposed control scheme. In section IV, the proposed technique's implementation on a nuclear power plant model is presented and its effectiveness discussed referring to simulation results. Conclusions are drawn in Section V indicating the paper's main contributions.

\section{Dynamic Model of a PWR Nuclear Power Plant}

The dynamic model of a PWR-type nuclear power plant is briefly discussed here. The different subsections of the integrated model have been studied in detail in [45], [47][49]. The integrated model has been analysed and verified with simulated as well as plant data in [46]. The key variables of the model equations given below are described near their first occurrence, while the constant model parameters are all described, along with their units, in the nomenclature section.

\section{A. Point-Kinetics Reactor Core Model}

The dynamic model of a nuclear reactor core is modelled using the point-kinetics equation coupled with six groups of delayed neutrons precursor. It is given by

$$
\begin{aligned}
\frac{d P_{n}}{d t} & =\frac{\rho_{t}-\sum_{i=1}^{6} \beta_{i}}{\Lambda} P_{n}+\sum_{i=1}^{6} \frac{\beta_{i}}{\Lambda} C_{i n}, \\
\frac{d C_{i n}}{d t} & =\lambda_{i} P_{n}-\lambda_{i} C_{i n}, \quad i=1,2, \ldots 6,
\end{aligned}
$$

where $P_{n}$ and $C_{i n}$ represent the normalized power and delayed neutron precursor concentration of the $i^{\text {th }}$ group, respectively.

\section{B. Thermal-Hydraulics Model}

The core thermal-hydraulics behaviour is governed by the Mann's model which considers two lumps for the coolant node and one lump for the fuel node [47]. It is represented as

$$
\begin{aligned}
\frac{d T_{f}}{d t} & =H_{f} P_{n}-\frac{1}{\tau_{f}}\left(T_{f}-T_{c 1}\right), \\
\frac{d T_{c 1}}{d t} & =H_{c} P_{n}+\frac{1}{\tau_{c}}\left(T_{f}-T_{c 1}\right)-\frac{2}{\tau_{r}}\left(T_{c 1}-T_{c i n}\right), \\
\frac{d T_{c 2}}{d t} & =H_{c} P_{n}+\frac{1}{\tau_{c}}\left(T_{f}-T_{c 1}\right)-\frac{2}{\tau_{r}}\left(T_{c 2}-T_{c 1}\right),
\end{aligned}
$$

where $T_{f}, T_{c 1}$, and $T_{c 2}$ denote the temperatures of fuel, coolant node 1 , and node 2 , respectively.

\section{Piping \& Plenum Model}

Different piping and plenum of reactor-core and steam generator (SG) can be represented by first order ordinary differential equations as

$$
\begin{aligned}
\frac{d T_{r x u}}{d t} & =\frac{1}{\tau_{r x u}}\left(T_{c 2}-T_{r x u}\right), \\
\frac{d T_{h o t}}{d t} & =\frac{1}{\tau_{h o t}}\left(T_{r x u}-T_{\text {hot }}\right), \\
\frac{d T_{s g i}}{d t} & =\frac{1}{\tau_{s g i}}\left(T_{\text {hot }}-T_{\text {sgi }}\right), \\
\frac{d T_{\text {sgu }}}{d t} & =\frac{1}{\tau_{\text {sgu }}}\left(T_{p 2}-T_{\text {sgu }}\right), \\
\frac{d T_{\text {cold }}}{d t} & =\frac{1}{\tau_{\text {cold }}}\left(T_{\text {sgu }}-T_{\text {cold }}\right), \\
\frac{d T_{r x i}}{d t} & =\frac{1}{\tau_{r x i}}\left(T_{\text {cold }}-T_{r x i}\right),
\end{aligned}
$$

where $T_{r x i}, T_{r x u}, T_{h o t}, T_{\text {cold }}, T_{s g i}$, and $T_{s g u}$ are temperatures of lower-plenum, upper-plenum, hot-leg, cold-leg, SG inletplenum, and SG outlet-plenum, respectively.

\section{Steam Generator Model}

A steam generator (SG) can be represented by five nodes in which the primary coolant lump (PCL) and metal tube lump (MTL) are represented by two nodes each [48]. It is given by

$$
\begin{aligned}
\frac{d T_{p 1}}{d t} & =\frac{1}{\tau_{p 1}}\left(T_{s g i}-T_{p 1}\right)-\frac{1}{\tau_{p m 1}}\left(T_{p 1}-T_{m 1}\right), \\
\frac{d T_{p 2}}{d t} & =\frac{1}{\tau_{p 2}}\left(T_{p 1}-T_{p 2}\right)-\frac{1}{\tau_{p m 2}}\left(T_{p 2}-T_{m 2}\right), \\
\frac{d T_{m 1}}{d t} & =\frac{1}{\tau_{m p 1}}\left(T_{p 1}-T_{m 1}\right)-\frac{1}{\tau_{m s 1}}\left(T_{m 1}-T_{s}\right), \\
\frac{d T_{m 2}}{d t} & =\frac{1}{\tau_{m p 2}}\left(T_{p 2}-T_{m 2}\right)-\frac{1}{\tau_{m s 2}}\left(T_{m 2}-T_{s}\right) .
\end{aligned}
$$

where $T_{p 1}, T_{p 2}, T_{m 1}$, and $T_{m 2}$ are temperatures of PCL 1, PCL 2, MTL 1, and MTL 2, respectively. The secondary coolant lump (SCL) to represent steam pressure $\left(p_{s}\right)$ can be obtained by balancing mass, volume, and heat as

$$
\begin{gathered}
\frac{d p_{s}}{d t}=\frac{1}{K_{s}}\left[U_{m s 1} S_{m s 1}\left(T_{m 1}-T_{s}\right)+U_{m s 2} S_{m s 2}\left(T_{m 2}-T_{s}\right)\right. \\
\left.-\left(\dot{m}_{s o} h_{s s}-\dot{m}_{f w} c_{p f w} T_{f w}\right)\right] .
\end{gathered}
$$


where,

$$
K_{s}=m_{w s} \frac{\partial h_{w s}}{\partial p_{s}}+m_{s s} \frac{\partial h_{s s}}{\partial p_{s}}-m_{w s}\left(\frac{h_{w s}-h_{s s}}{\nu_{w s}-\nu_{s s}}\right) \frac{\partial \nu_{s s}}{\partial p_{s}}
$$

It is considered that the feed-water inlet flow is adjusted to match steam outlet flow and the latter is dependent only on steam pressure. Thus, the steam outlet flow is given by

$$
\dot{m}_{s o}=C_{t g} p_{s} .
$$

\section{E. Pressurizer Model}

The two-phase pressurizer $\left(p_{p}\right)$ dynamical model can be obtained by applying volume and energy balances of water and steam mixture with steam compressibility as [49]

$$
\begin{gathered}
Q_{\text {heat }}+\dot{m}_{\text {sur }}\left(\frac{p_{p} \nu_{s}}{J_{p} C_{1 p}}+\frac{h_{\bar{w}}}{C_{1 p}}\right)+ \\
\frac{d p_{p}}{d t}=\frac{\dot{m}_{s p r}\left(h_{s p r}-h_{w}+\frac{h_{\bar{w}}}{C_{1 p}}+\frac{p_{p} \nu_{w}}{J_{p} C_{1 p}}\right)}{m_{w}\left(K_{3 p}+\frac{K_{4 p} p_{p}}{J_{p}}\right)+\frac{m_{s} K_{4 p} p_{p}}{J_{p}}-} \\
\frac{V_{w}}{J_{p}}+\frac{C_{2 p}}{C_{1 p}}\left(h_{\bar{w}}+\frac{p_{p} \nu_{s}}{J_{p}}\right)
\end{gathered}
$$

The equation of water level $\left(l_{w}\right)$ in the pressurizer can be obtained by applying mass balance equation on water and steam phase as

$$
\begin{aligned}
\frac{d l_{w}}{d t}= & \frac{1}{d_{s} A_{p}}\left(\left(A_{p}\left(l-l_{w}\right) K_{2 p}-\frac{C_{2 p}}{C_{1 p}}\right) \frac{d p_{p}}{d t}\right. \\
& \left.+\frac{1}{C_{1 p}^{2}}\left(C_{2 p} \frac{d p_{p}}{d t}-\dot{m}_{\text {sur }}-\dot{m}_{\text {spr }}\right)+\frac{\dot{m}_{\text {sur }}}{C_{1 p}}\right)
\end{aligned}
$$

where the surge rate can be represented as

$$
\dot{m}_{\text {sur }}=\sum_{j=1}^{N} V_{j} \vartheta_{j} \frac{d T_{j}}{d t}
$$

The index $j=1$ to $N$ represents coolant node temperatures in the following order, reactor lower plenum, coolant node 1 and 2, rector upper plenum, hot-leg, SG inlet plenum, PCL 1 and 2, SG outlet plenum, and cold-leg, respectively. The intermediate variables are defined as

$$
\begin{aligned}
& C_{1 p}=\frac{d_{w}}{d_{s}}-1 \\
& C_{2 p}=A_{p}\left(l-l_{w}\right) \frac{d_{w}}{d_{s}} K_{2 p}+A_{p} l_{w} K_{1 p} \\
& K_{1 p}=\frac{\partial d_{w}}{\partial p_{p}} ; K_{2 p}=\frac{\partial d_{s}}{\partial p_{p}} ; K_{3 p}=\frac{\partial h_{w}}{\partial p_{p}} ; K_{4 p}=\frac{\partial \nu_{s}}{\partial p_{p}} ;
\end{aligned}
$$

\section{F. Turbine Model}

The dynamical model of a turbine consists of the highpressure turbine, intermediate-pressure turbine, re-heater, and low-pressure turbine as [45]

$$
\begin{array}{r}
\frac{d^{2} P_{h p}}{d t}+\left(\frac{O_{r v}+\tau_{i p}}{\tau_{h p} \tau_{i p}}\right) \frac{d P_{h p}}{d t}+\left(\frac{O_{r v}}{\tau_{h p} \tau_{i p}}\right) P_{h p}=\left(\frac{O_{r v} F_{h p}}{\tau_{h p} \tau_{i p}}\right) \overline{\dot{m}}_{s o} \\
+\left(\frac{\left(1+\kappa_{h p}\right) F_{h p}}{\tau_{h p}}\right) \frac{d \dot{m}_{s o}}{d t} \\
\frac{d^{2} P_{i p}}{d t}+\left(\frac{O_{r v} \tau_{h p}+\tau_{i p}}{\tau_{h p} \tau_{i p}}\right) \frac{d P_{i p}}{d t}+\left(\frac{O_{r v}}{\tau_{h p} \tau_{i_{p}}}\right) P_{i p}=\left(\frac{O_{r v} F_{i p}}{\tau_{h p} \tau_{i p}}\right) \overline{\dot{m}}_{s o} \\
\frac{d^{3} P_{l p}}{d t}+\left(\frac{O_{r v} \tau_{h p}+\tau_{i p}}{\tau_{h p} \tau_{i p}}+\frac{1}{\tau_{l p}}\right) \frac{d^{2} P_{l p}}{d t}+\left(\frac{O_{r v}\left(\tau_{l p}+\tau_{h p}\right)+\tau_{i p}}{\tau_{h p} \tau_{i p} \tau_{l p}}\right) \\
\frac{d P_{l p}}{d t}+\left(\frac{O_{r v}}{\tau_{h p} \tau_{i p} \tau_{l p}}\right) P_{l p}=O_{r v} F_{l p} \overline{\dot{m}}_{s o}
\end{array}
$$

where the steam flow in turbine is $\overline{\dot{m}}_{s o}=\dot{m}_{s o} / \dot{m}_{\text {sor }}, \dot{m}_{\text {sor }}$ is the rated steam mass flow rate. $P_{h p}, P_{i p}$, and $P_{l p}$ are mechanical power output of high-pressure, intermediate-pressure, and low-pressure turbine, respectively. Thus, the total mechanical output of the turbine is computed as

$$
P_{\text {tur }}=P_{h p}+P_{i p}+P_{l p} .
$$

The turbine-governor model consists of a turbine speed control system which produces a rate of change in turbine speed following the difference in the demand power $\left(P_{d e m}\right)$ and turbine output power $\left(P_{t u r}\right)$ [49]. It is given by

$$
\frac{d \omega_{t u r}}{d t}=\frac{P_{t u r}-P_{d e m}}{(2 \pi)^{2} J_{t u r} \omega_{t u r} I_{t g}}
$$

where $\omega_{t u r}$ is the turbine speed.

\section{G. Reactivity Model}

The reactivity model consists of reactivity feedback to include effects of variation in fuel and coolant temperatures and primary coolant system pressure in addition to the reactivity due to rod movement. The total reactivity $\left(\rho_{t}\right)$ is given by

$$
\rho_{t}=\rho_{\text {rod }}+\alpha_{f} T_{f}+\alpha_{c} T_{c 1}+\alpha_{c} T_{c 1}+\alpha_{p} p_{p} .
$$

\section{H. Sensors}

1) Ex-core Detectors: The global neutronic power in a reactor can be monitored using ex-core detectors and their associated amplifiers [50]. The ex-core detector produces a current signal $\left(i_{l o}\right)$ proportional to the total power. The logarithmically amplified current is sensed as

$$
\tau_{1} \tau_{2} \frac{d^{2} i_{l o}}{d t^{2}}+\left(\tau_{1}+\tau_{2}\right) \frac{d i_{l o}}{d t}+i_{l o}=K_{l o} \log _{10}\left(\kappa_{l o} P_{n}\right)
$$

2) Resistance Temperature Detector: Resistance temperature detectors (RTD) are used to measure the coolant temperature at the inlet $\left(T_{r t d 1}\right)$ and outlet $\left(T_{r t d 2}\right)$ as

$$
\begin{aligned}
& \frac{d T_{r t d 1}}{d t}=\frac{1}{\tau_{r t d}}\left(-T_{r t d 1}+2 T_{c 1}-T_{r x i}\right) \\
& \frac{d T_{r t d 2}}{d t}=\frac{1}{\tau_{r t d}}\left(-T_{r t d 2}+2 T_{c 2}-T_{r x u}\right)
\end{aligned}
$$

A proportional current signal $\left(i_{r t d}\right)$ can be obtained from the sensed RTD signals as

$$
i_{r t d}=K_{r t d} \frac{\left(\left(\left(T_{r t d 1}+T_{r t d 2}\right) / 2\right)-T_{r x i 0}\right)}{\left(T_{r x u 0}-T_{r x i 0}\right)}+4
$$




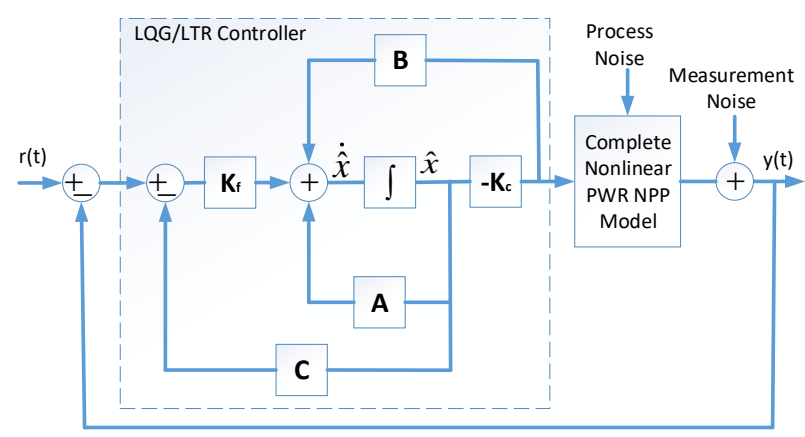

Fig. 1: Block diagram of the LQG/LTR control scheme.

\section{Actuators}

1) Control Rod: The change in reactivity due to control rod movement $\left(\rho_{\text {rod }}\right)$ is related to the rod movement speed $\left(v_{\text {rod }}\right)$ through the worth of the control rod. The dynamics of control rod is given by

$$
\frac{d \rho_{\text {rod }}}{d t}=G v_{\text {rod }}
$$

2) Turbine-Governor Valve: The turbine-governor control valve dynamics can be described by a second order differential equation in which the valve coefficient $\left(C_{t g}\right)$ can be adjusted using the input signal to the valve $\left(u_{t g}\right)$ as

$$
\frac{d^{2} C_{t g}}{d t^{2}}+2 \zeta_{t g} \varpi_{t g} \frac{d C_{t g}}{d t}+\varpi_{t g}^{2} C_{t g}=\varpi_{t g}^{2} K_{t g} u_{t g}
$$

\section{Proposed Control Approach}

LQR is an optimal full state-feedback controller which, under ideal conditions, guarantees an infinite gain margin and a phase margin of 60 degrees. LQG is a combination of LQR with Kalman filter estimated states for computing a control law that is optimal in the presence of white noise measurement and process noise. To improve the performance and robustness, either the Kalman filter gain matrix or the regulator gain matrix can be modified using the LTR approach [35]. The block diagram of the classical LQG/LTR scheme applied to the PWR-type nuclear power plant is shown in Fig. 1. LQI is a variant of $L Q R$ with an integrator to ensure zero steadystate error. It computes the control law using LQR with an added integral regulation of the output variable. Employing the concept of LQI, LQG, and LTR, a new modified LQGI/LTR approach is proposed here. The scheme first designs an LQILQG control scheme and then incorporates the LTR technique. The proposed scheme inherits the features of LQI, LQG, and LTR schemes. The block diagram of the proposed LQGI/LTR scheme applied to the PWR-type nuclear power plant is depicted in Fig. 2.

\section{A. Linearization}

The overall nonlinear system given by (1-34) can be linearized and represented in standard state-space form as

$$
\begin{aligned}
\dot{x}(t) & =A x(t)+B u(t), \\
y(t) & =C x(t)
\end{aligned}
$$

where $A \in \mathbb{R}^{n \times n}, B \in \mathbb{R}^{n \times m}$, and $C \in \mathbb{R}^{l \times n}$ are system matrices. $u(t) \in \mathbb{R}^{m}$, and $y(t) \in \mathbb{R}^{l}$, and $x(t) \in \mathbb{R}^{n}$, respectively represent control input, system output, and state, respectively. They are given by,

$$
\begin{aligned}
& u(t)=\left[\begin{array}{lllll}
\delta v_{\text {rod }} & \delta u_{\text {tg }} & \delta Q_{\text {heat }} & \delta \dot{m}_{\text {spr }} & \delta \dot{m}_{\text {sur }}
\end{array}\right]^{T} \\
& y(t)=\left[\begin{array}{llllll}
\delta i_{\text {lo }} & \delta i_{\text {rtd }} & \delta p_{s} & \delta p_{p} & \delta l_{w} & \delta \omega_{\text {tur }}
\end{array}\right]^{T}
\end{aligned}
$$

and

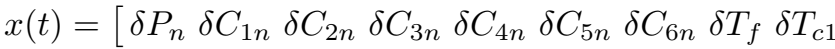

$\delta T_{c 2} \delta T_{\text {rxu }} \delta T_{\text {hot }} \delta T_{\text {sgi }} \delta T_{\text {sgu }} \delta T_{\text {cold }} \delta T_{\text {rxi }} \delta T_{p 1} \delta T_{p 2}$

$\delta T_{m 1} \delta T_{m 2} \delta p_{s} \delta p_{p} \delta l_{w} \delta P_{h p} \delta \dot{P}_{h p} \delta P_{i p} \delta \dot{P}_{i p} \delta P_{l p} \delta \dot{P}_{l p}$

$\left.\delta \ddot{P}_{l p} \delta \omega_{\text {tur }} \delta i_{\text {lo }} \delta \dot{i}_{l o} \delta T_{\text {rtd } 1} \delta T_{\text {rtd } 2} \delta \rho_{\text {rod }} \delta C_{t g} \delta \dot{C}_{t g}\right]^{T}$.

where $\delta$ represents deviation from the steady state value. It is to note that the eigenvalues of the linearized system matrices capture the time constants of the system and thus, they are taken into account by the controller gain matrices through the model-based design procedure, as explained in later sections.

\section{B. System Representation and State Augmentation}

The linear time invariant system can also be represented as

$$
\begin{aligned}
\dot{x}(t) & =A x(t)+B u(t)+\Gamma \omega(t), \\
y(t) & =C x(t)+v(t)
\end{aligned}
$$

where $\Gamma \in \mathbb{R}^{n \times m}$ is disturbance input matrix. $\omega(t)$ and $v(t)$ are process noise and measurement noise with zero mean and covariance matrices, $E\left(\omega(t) \omega(t)^{T}\right)=\Xi$ and $E\left(v(t) v(t)^{T}\right)=\Theta$, respectively. To ensure zero steady-state error during reference tracking an integral action can be incorporated in the feed-forward path using state augmentation. The LQR controller can then be designed for the augmented system.

Define an error variable between reference $(r(t))$ and output $(y(t))$ as

$$
\dot{e}(t)=r(t)-y(t)
$$

Considering $r(t)$ as constant at steady-state, one can rewrite the augmented model in terms of error dynamics between the current and the steady-state value consisting error variable as an additional state as

$$
\begin{array}{r}
{\left[\begin{array}{c}
\dot{x}_{e}(t) \\
\dot{e}_{e}(t)
\end{array}\right]=\left[\begin{array}{cc}
A & 0 \\
-C & 0
\end{array}\right]\left[\begin{array}{l}
x_{e}(t) \\
e_{e}(t)
\end{array}\right]+\left[\begin{array}{c}
B \\
0
\end{array}\right] u_{e}(t)+} \\
{\left[\begin{array}{c}
\Gamma \\
0
\end{array}\right] \omega_{e}(t)+\left[\begin{array}{c}
0 \\
-I
\end{array}\right] v_{e}(t)}
\end{array}
$$

where $x_{e}=x(t)-x(\infty)$ and similarly other variables with subscript $e$ are defined. Define, $\xi(t)=\left[\begin{array}{l}x_{e}(t) \\ e_{e}(t)\end{array}\right]$, one can write,

$$
\dot{\xi}(t)=\bar{A} \xi(t)+\bar{B} u_{e}(t)+\bar{\Gamma} \omega_{e}(t)+\Pi v_{e}(t)
$$

where $\bar{A}=\left[\begin{array}{cc}A & 0 \\ -C & 0\end{array}\right] ; \bar{B}=\left[\begin{array}{c}B \\ 0\end{array}\right] ; \bar{\Gamma}\left[\begin{array}{l}\Gamma \\ 0\end{array}\right] ; \Pi=\left[\begin{array}{c}0 \\ -I\end{array}\right]$.

\section{Linear Quadratic Gaussian Integrator}

The design of an LQGI involves two steps, the first step is to design a Kalman filter for state estimation and the second step is to design an optimal state-feedback control for the augmented system using an LQR. The Kalman filter and 
the LQR can be designed independently using the separation principle.

1) Kalman Filter: The Kalman filter estimation problem is to find an optimal state estimate $\hat{x}(t)$ such that the following error covariance is minimized:

$$
J_{1}=\lim _{t \rightarrow \infty} E\left\{(x-\hat{x})(x-\hat{x})^{T}\right\}
$$

The Kalman filtering problem is estimated by computing the Kalman gain $K_{f}$ given by

$$
K_{f}=P_{f} C^{T} \Theta^{-1}
$$

where $P_{f}$ is a symmetric positive-semidefinite matrix and can be computed using the solution of following Algebraic Riccati Equation (ARE) as

$$
A P_{f}+P_{f} A^{T}+\Gamma \Xi \Gamma^{T}-P_{f} C^{T} \Theta^{-1} C P_{f}=0
$$

Thus, the estimated states $\dot{\hat{x}}(t)$ are given by,

$$
\dot{\hat{x}}(t)=A \hat{x}(t)+B u(t)+K_{f}(y(t)-C \hat{x}(t))
$$

2) Linear Quadratic Regulator: The estimated states are then employed to implement optimal state-feedback control for the augmented system using LQR. The LQR design computes an optimal control input by minimizing the following cost function

$$
J_{2}=\int_{0}^{\infty}\left(\hat{\xi}^{T} Q \hat{\xi}+u_{e}^{T} R u_{e}\right) d t
$$

where $Q$ and $R$ are positive-semidefinite and positive-definite weighing matrices, respectively. The cost function can be minimized by finding the solution of the following ARE to calculate optimal regulator feedback gain. The ARE is given by

$$
\bar{A}^{T} P_{c}+P_{c} \bar{A}+Q-P_{c} \bar{B} R^{-1} \bar{B}^{T} P_{c}=0
$$

where $P_{c}$ is a symmetric positive semidefinite matrix. The optimal regulator feedback gain is computed as

$$
\bar{K}=\left[K_{c}-K_{I}\right]=R^{-1} \bar{B}^{T} P_{c}
$$

The control law for error dynamics is then given by

$$
u_{e}(t)=-R^{-1} \bar{B}^{T} P_{c} \hat{\xi}(t)=-R^{-1} \bar{B}^{T} P_{c}\left[\begin{array}{c}
\hat{x}_{e}(t) \\
\hat{e}_{e}(t)
\end{array}\right]
$$

Thus, the state-feedback control law for the system is given by,

$$
u(t)=-R^{-1} \bar{B}^{T} P_{c}\left[\begin{array}{l}
\hat{x}(t) \\
\hat{e}(t)
\end{array}\right]=-K_{c} \hat{x}(t)+K_{I} \hat{e}(t)
$$

The optimal state-feedback control law is implemented using the estimated states.

\section{Loop Transfer Recovery}

Due to the presence of the Kalman filter, the noise covariance matrices, and its associated weights, the performance of LQG is affected. Often, the dynamics of the Kalman filters are not faster than the plant dynamics. These will lead to a reduction in the stability margin and even to instability with a small disturbance. The idea of LTR design is to use a fictitious gain coefficient $q$ called as recovery gain, and then gradually increase $q \rightarrow \infty$, such that the final loop-transfer function approximates to the state-feedback loop transfer function designed by the LQR [35]. The LTR technique modifies the gains of the return ratio to regain the robustness by an iterative selection of either the regulator or the Kalman filter [34]. If the gains of the return ratio are shaped at the output of the plant by tuning the regulator gains then the technique is called as the LTR-at-the-output approach. On the other hand, if the gains of the return ratio are shaped at the input of the plant by tuning the Kalman filter matrix then it is called as the LTR-at-the-input approach [35].

1) LTR-at-the-output: In this approach, the gains of the LQR are shaped so that the resultant filter transfer function has guaranteed stability margins. The open-loop system with the LQG return ratio at the output is given by

$$
G(s)=C(s I-A)^{-1} B K_{c}\left(s I-A+B K_{c}+K_{f} C\right)^{-1} K_{f}(50)
$$

The following procedure is followed [35]:

- First, select a Kalman filter by a suitable choice of the weighting matrices $\Gamma, \Xi$, and $\Theta$ such that a satisfactory return ratio at the output is obtained.

- Select $Q=q C^{T} C$ and $R=I$ and increase recovery gain $q$ until the ideal return ratio at the output is recovered in the closed-loop system.

The ideal return ratio at the output is given by

$$
\lim _{q \rightarrow \infty} G^{\text {out }}(s)=C(s I-A)^{-1} K_{f}
$$

2) LTR-at-the-input: In this approach, the gains of the Kalman filter matrices are shaped so that the resultant filter transfer function has guaranteed stability margins. The openloop system with the LQG return ratio at the input is given by

$$
G(s)=K_{c}\left(s I-A+B K_{c}+K_{f} C\right)^{-1} K_{f} C(s I-A)^{-1} B(52)
$$

The following procedure is followed [35]:

- First, select the LQR regulator by a suitable choice of the weighting matrices $Q$ and $R$ such that good performance and robustness with state-feedback is obtained.

- Select $\Gamma=B, \Xi=q \Xi$ and $\Theta=I$ and increase recovery gain $q$ until the desired state-feedback properties are recovered in the closed-loop system.

The ideal return ratio at the input is achieved when all the states are available for measurement and it is given by

$$
\lim _{q \rightarrow \infty} G^{i n p}(s)=K_{c}(s I-A)^{-1} B
$$

\section{E. Control Performance Assessment}

The control performance can be numerically analysed based on the following factors presented in this paragraph. The first one is the percentage root mean squared error (PRMSE) calculated on the basis of the tracking error. The effect of control action on the input is analysed by computing the total variation of input (TVI) which is a measure of smoothness of 


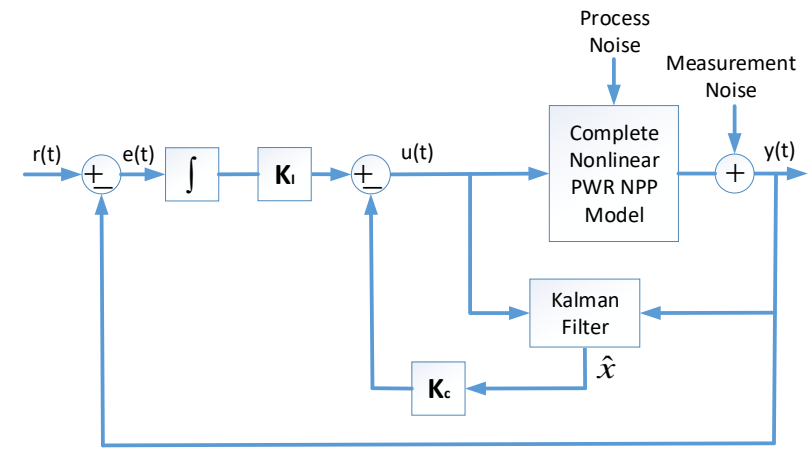

Fig. 2: Block diagram of the LQGI/LTR control scheme.

a signal and the $\mathcal{L}_{2}$-norm of input $\left(\mathcal{L}_{2} \mathrm{NI}\right)$ which is a measure of control energy. These are given by

$$
\begin{aligned}
\text { PRMSE } & =\sqrt{\frac{1}{N} \sum_{k=1}^{N}(y[k]-r[k])^{2}} \times 100 \%, \\
T V I & =\sum_{k=1}^{N}|(u[k+1]-u[k])|, \\
\mathcal{L}_{2} N I & =\sqrt{\sum_{k=1}^{N}(u[k])^{2} .}
\end{aligned}
$$

where $N$ denotes the total number of samples.

\section{RESULTS AND DISCUSSION}

In this work, the LTR-at-the-input design approach is considered in which first the LQR is designed by selecting $Q$ and $R$ matrices to achieve good performance. Large positive diagonal values for $Q$ result in the poles of the closed-loop system to be further away from the origin and the output, therefore, tracks the reference rapidly. Conversely, large positive diagonal values for $R$ result in the poles of the closed-loop system to be closer to the origin and the output, therefore, tracks the reference slowly. In the case of LTR, the performance of the target feedback loop (TFL) is analysed by Nyquist and Bode plots and they are shown in Figs. 3 and 4, respectively. The values of $\Gamma, \Xi$, and $\Theta$ are selected as $\Gamma=B, \Xi=q \Xi$ and $\Theta=I$. The plots of the loop transfer function matrix for different values of $q$ are plotted and compared with those of the TFL as shown in Figs. 3 and 4. It can be seen that as $q \rightarrow \infty$, the loop transfer function approaches the ideal return ratio given by the TFL. Thus, if the loop transfer function meets the desired specifications, then the procedure will result in a compensator that will also meet the specifications. The better recovery is generally obtained for a large $q$.

The simulation results were obtained by testing the performance of the designed controllers under various conditions. The controllers are designed after linearizing the nonlinear PWR system operating at 1 fractional full power (FFP). The designed linear controller is then tested on the nonlinear PWRtype nuclear power plant model under parametric variations and disturbances of the ramp and sinusoidal nature. These are given by

$$
\begin{aligned}
\omega_{1}(t)= & 10^{-5}\left(\sin \left(10^{-3} t\right)+2 \sin \left(10^{-2} t\right)+3 \sin \left(10^{-1} t(t) 7\right)\right. \\
\omega_{2}(t)= & -10^{-3}(s(t-100)-s(t-700)+s(t-1000) \\
& -s(t-1600)) \\
\omega_{3}(t)= & -0.5 \omega_{2}(t)
\end{aligned}
$$

where the disturbance $\omega_{1}(t)$ is in the total reactivity, the uncertainty $\omega_{2}(t)$ is in the feed-water inlet temperature, and the uncertainty $\omega_{3}(t)$ is in the surge flow rate. Here, $s(t)$ denotes a unit ramp signal. Four different control-loops were considered in the nuclear power plant: reactor core power loop, steam generator loop, pressurizer loop, and turbine speed loop. In each case, the results of the proposed control scheme are compared with different control techniques such as PID, LQG, and LQG/LTR. The definitions of different input and output variables and the values of different tuning parameters for various loops are given in Table I. The nuclear power plant model parameters and the steady-state values of different variables at the operating point are summarized in Table A.1 in the Appendix.

\section{A. Load-Following Mode of operation}

The performance of the proposed controller is tested for the load-following mode of operation of a PWR-type nuclear power plant. A typical load-following transient is considered as follows: Initially, for $60 \mathrm{~s}$, the power is maintained at 1 FFP; then, it is changed to $1.2 \mathrm{FFP}$ in $240 \mathrm{~s}$ at $5 \% / \mathrm{min}$; held at $1.2 \mathrm{FFP}$ for $460 \mathrm{~s}$; then, it is decreased to its initial value in $240 \mathrm{~s}$ and held at $1 \mathrm{FFP}$ for $360 \mathrm{~s}$; then, it is changed to 0.8 FFP in $240 \mathrm{~s}$; held at $0.8 \mathrm{FFP}$ for $360 \mathrm{~s}$; then, it is increased to its initial value in $240 \mathrm{~s}$ and held at 1 FFP for the rest of the duration. The reactor power can be controlled either through the ex-core detector current corresponding to measured power or RTD current corresponding to average coolant temperature. Here, both configurations are studied.

1) Power Loop: The variation in ex-core detector current corresponding to demand power is plotted in Fig. 5a. The variation in the control rod speed signal is shown in Fig. 5b. The performance of classical approaches, PID, LQG, LQG/LTR is also plotted. The proposed LQGI/LTR controller tracks the variation smoothly without any overshoot and provides zero steady-state error for a constant reference. Other controllers can track the changes in demand power, but they are unable to reject the disturbances. Table II numerically compares the control performance of different approaches. It is found that the value of PRMSE for the LQGI/LTR approach is lower than those of the other techniques at least by one order of magnitude. The values of $\mathcal{L}_{2} \mathrm{NI}$ and TVI is found to be comparable among all the approaches in which the LQG/LTR takes the minimum value. On the other hand, the LQGI/LTR takes slightly more control efforts with significantly better setpoint performance. Among all of them, the LQGI/LTR gives better set-point tracking without any peak overshoot, and its response is free from disturbances.

2) Temperature Loop: The variation in RTD current corresponding to demand power is plotted in Fig. 5c. The variation 


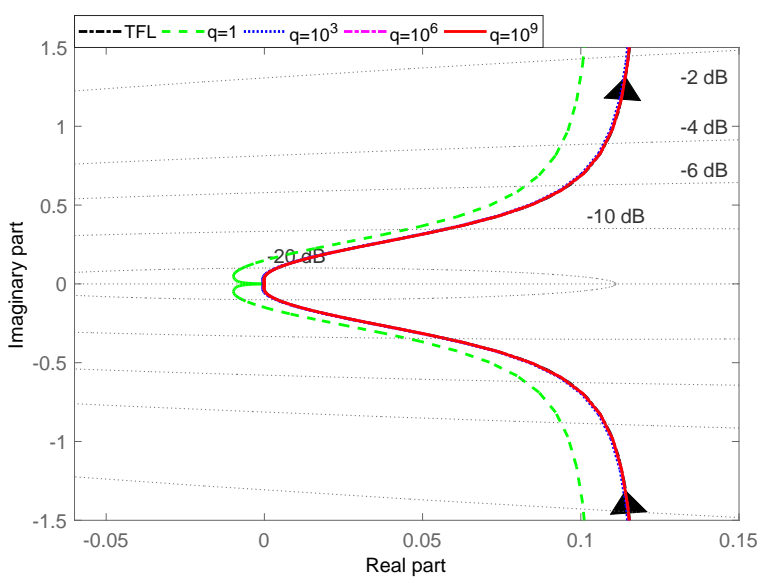

(a) Power loop.

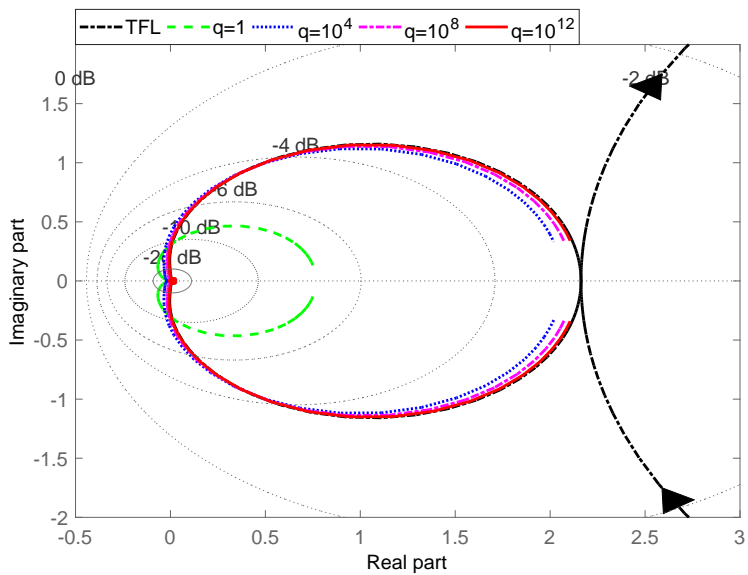

(c) Steam generator loop.

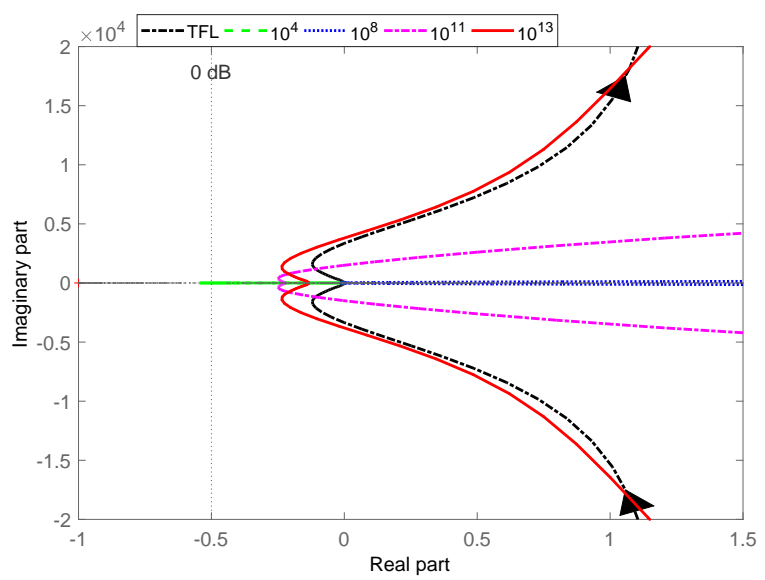

(e) Pressurizer level loop.

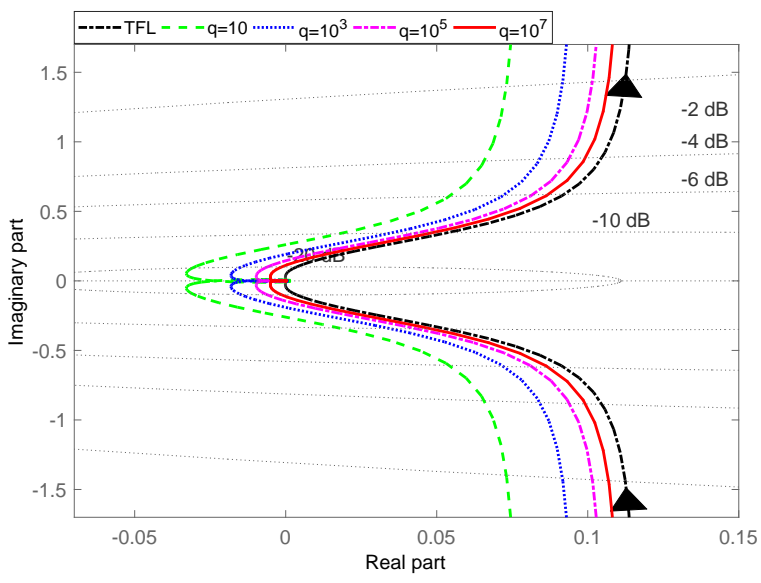

(b) Temperature loop.

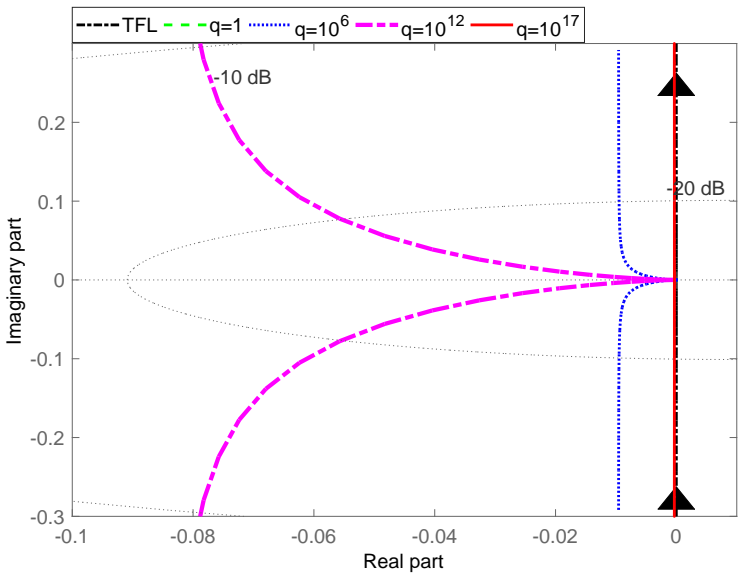

(d) Pressurizer pressure loop.

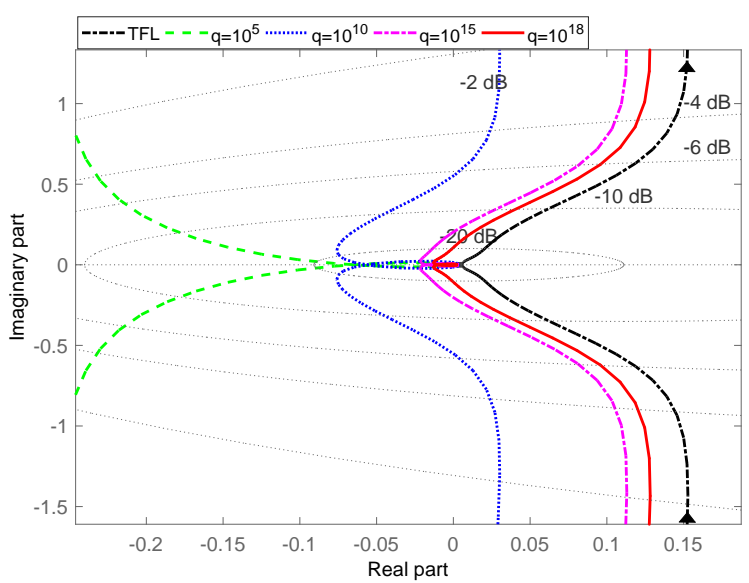

(f) Turbine speed loop.

Fig. 3: Nyquist plots for different values of recovery gain.

of the control rod speed signal is shown in Fig. 5d. The proposed LQGI/LTR controller tracks the variation smoothly without any overshoot with zero steady-state error. On the contrary, other controllers can track the changes in demand power, but, they are unable to reject the disturbances. The PID configuration tracks the variation with $4 \%$ overshoot. From
Table II, it is noted that the value of PRMSE for the LQGI/LTR approaches is lower than those of the other techniques. The control efforts in terms of $\mathcal{L}_{2} \mathrm{NI}$ and TVI are comparable for all the schemes in which the LQG takes the minimum value however it failed to handle the disturbances and uncertainties. The proposed technique gives a robust performance with 


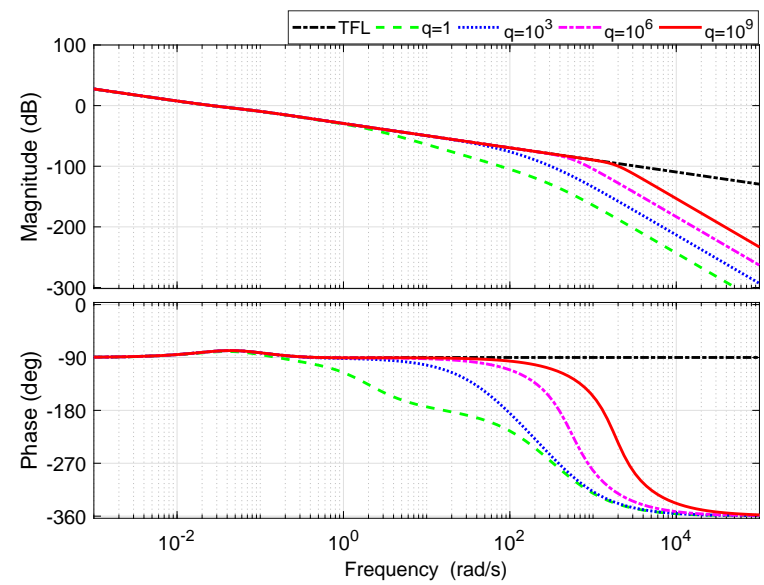

(a) Power loop.

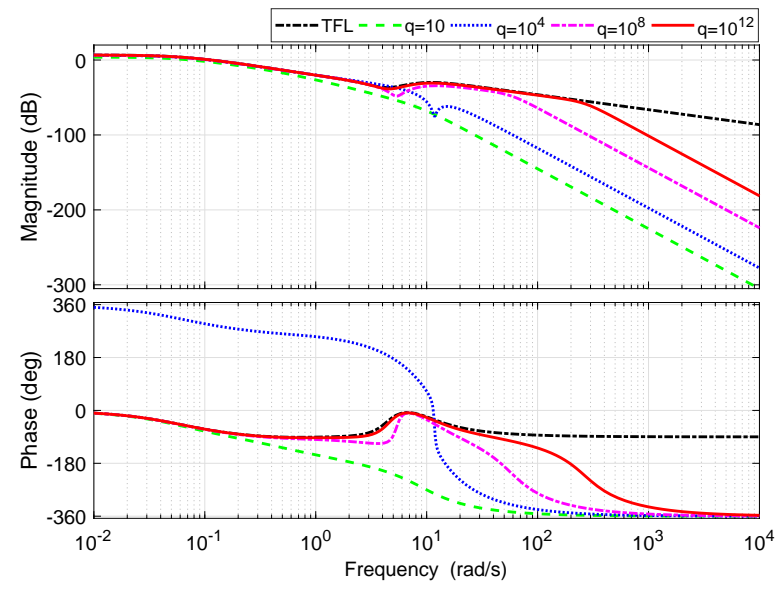

(c) Steam generator loop.

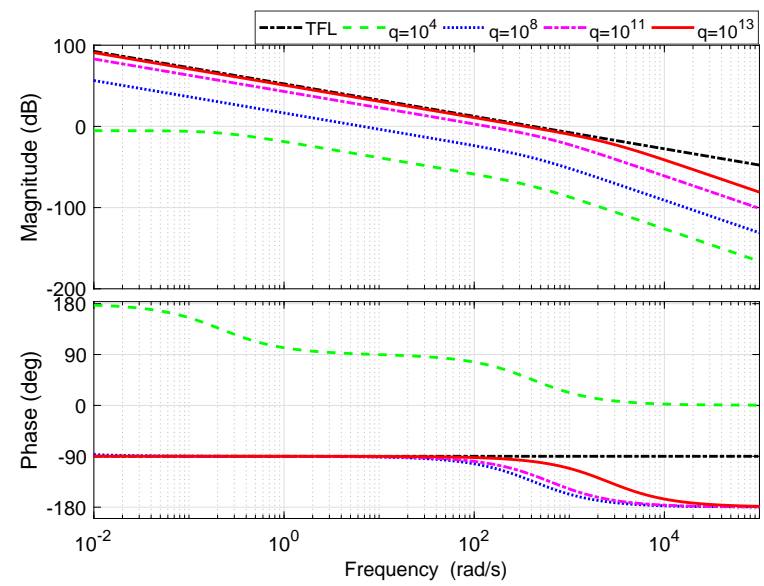

(e) Pressurizer level loop.

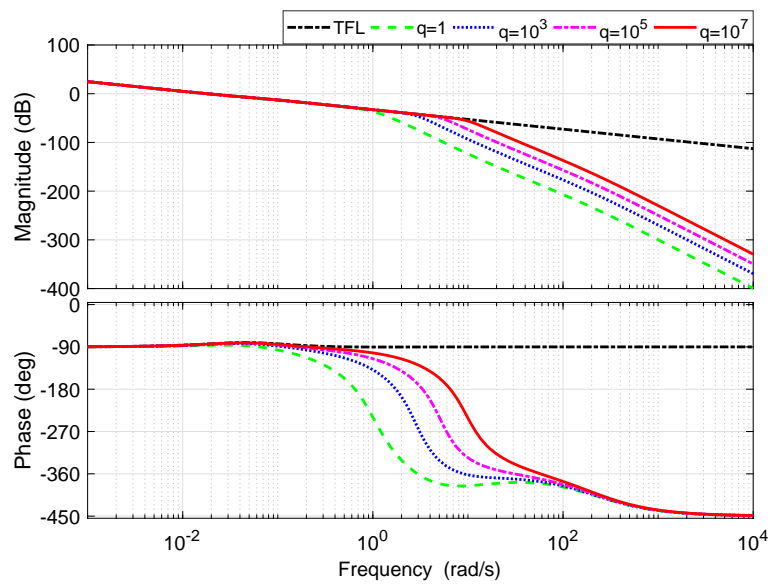

(b) Temperature loop.

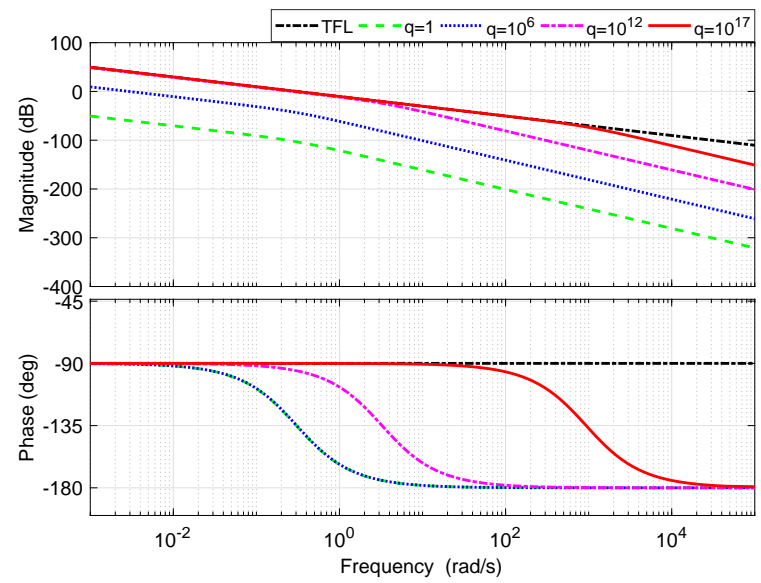

(d) Pressurizer pressure loop.

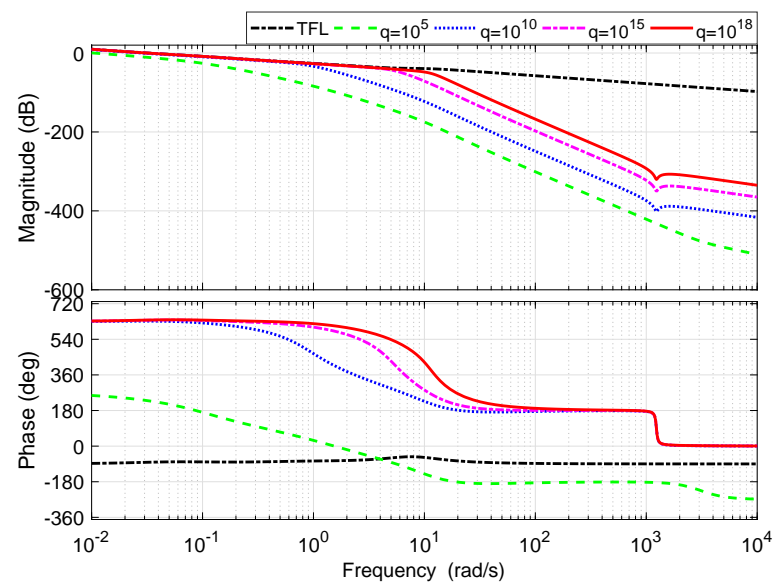

(f) Turbine speed loop.

Fig. 4: Bode plots for different values of recovery gain.

approximately the same control efforts.

\section{B. Steam Generator Loop}

The performance of the proposed technique is tested for a set-point change in the steam generator pressure. It is applied as follows: Initially, for $200 \mathrm{~s}$, the SG pressure is maintained at a steady-state value of $7.285 \mathrm{MPa}$; then, it is changed to $7.335 \mathrm{MPa}$ in $300 \mathrm{~s}$; held at $7.335 \mathrm{MPa}$ for $700 \mathrm{~s}$; then, it is reduced to its initial value in $300 \mathrm{~s}$ and held at $7.285 \mathrm{MPa}$ for the rest of the duration. Fig. 6a shows the performance of the proposed controller in set-point tracking. It is observed that the LQGI/LTR controller output can track the variation 
TABLE I: Tuning parameters for different control approaches

\begin{tabular}{|c|c|c|c|c|c|c|c|}
\hline \multicolumn{3}{|c|}{ Configuration } & \multicolumn{2}{c|}{ PID } & \multicolumn{2}{c|}{ LQG } & LTR \\
\hline Case & Input & Output & $K_{p}$ & $K_{i}$ & $Q$ & $R$ & $q$ \\
\hline A. 1 & $v_{\text {rod }}$ & $i_{l o}$ & $5.105 \times 10^{-2}$ & $8.996 \times 10^{-3}$ & $1 \times 10^{-3} I_{n}$ & $5 \times 10^{4} I_{m}$ & $1 \times 10^{9}$ \\
\hline A. 2 & $v_{\text {rod }}$ & $i_{r t d}$ & $1.986 \times 10^{-3}$ & $1.063 \times 10^{-5}$ & $1 \times 10^{-3} I_{n}$ & $1 \times 10^{5} I_{m}$ & $1 \times 10^{7}$ \\
\hline B & $u_{t g}$ & $p_{s}$ & $5.404 \times 10^{-1}$ & $1.185 \times 10^{-1}$ & $5 \times 10^{-2} I_{n}$ & $1 \times 10^{2} I_{m}$ & $1 \times 10^{12}$ \\
\hline C. 1 & $Q_{h e a t}$ & $p_{p}$ & $1.099 \times 10^{7}$ & $6.343 \times 10^{6}$ & $1 \times 10^{0} I_{n}$ & $1 \times 10^{-10} I_{m}$ & $1 \times 10^{17}$ \\
\hline C. 2 & $\dot{m}_{\text {spr }}$ & $p_{p}$ & $2.936 \times 10^{5}$ & $1.695 \times 10^{5}$ & $5 \times 10^{-3} I_{n}$ & $1 \times 10^{-8} I_{m}$ & $1 \times 10^{17}$ \\
\hline C. 3 & $\dot{m}_{\text {sur }}$ & $l_{w}$ & $2.408 \times 10^{3}$ & $2.615 \times 10^{3}$ & $1 \times 10^{6} I_{n}$ & $1 \times 10^{-5} I_{m}$ & $1 \times 10^{13}$ \\
\hline D & $u_{t g}$ & $\omega_{\text {tur }}$ & $6.472 \times 10^{2}$ & $8.359 \times 10^{0}$ & $1 \times 10^{0} I_{n}$ & $1 \times 10^{-2} I_{m}$ & $1 \times 10^{18}$ \\
\hline
\end{tabular}

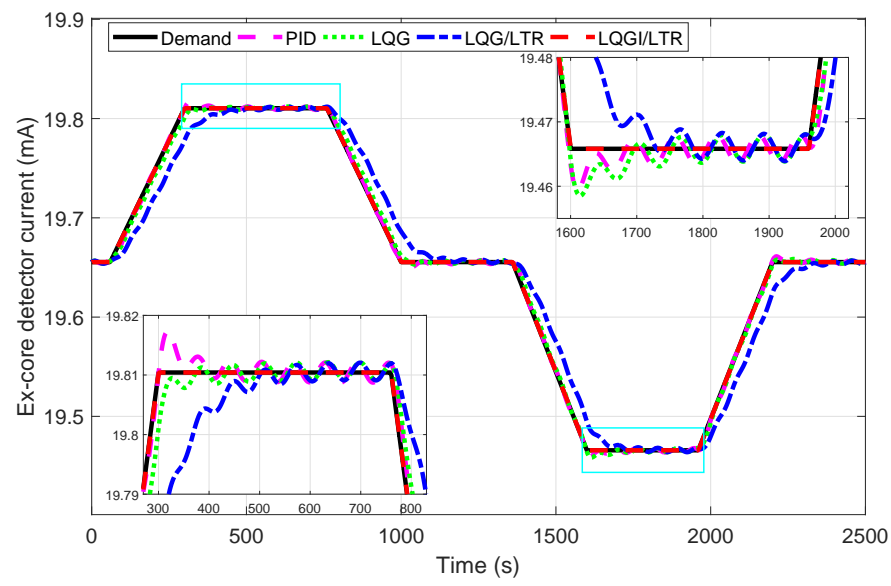

(a) Ex-core detector current.

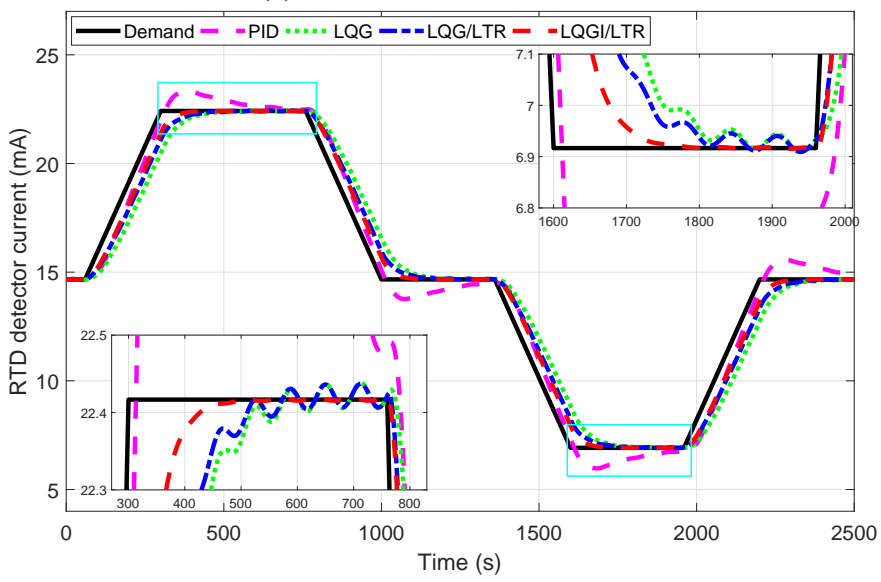

(c) RTD current.

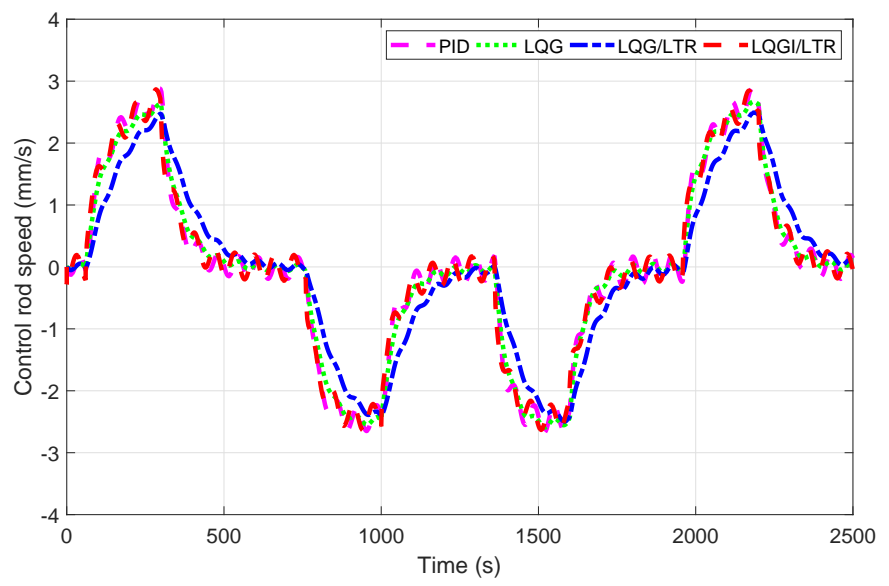

(b) Control rod speed movement.

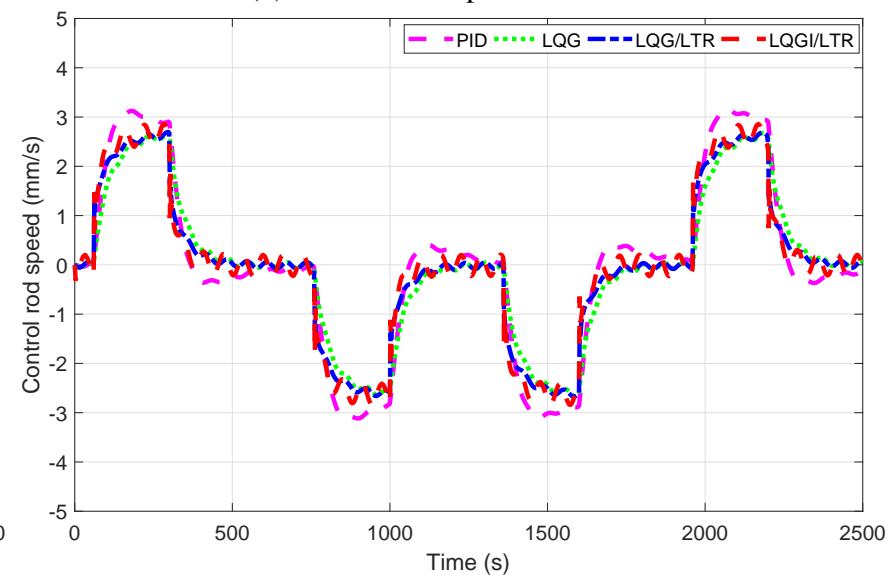

(d) Control rod speed movement.

Fig. 5: Variation of output and input signals during load following mode of operation.

smoothly as envisaged in the presence of uncertainties and can reject disturbances. The PID, LQG, and LQG/LTR controllers can track the set-point variation, but, they are unable to reject the disturbances. The LQG and LQG/LTR approaches give a steady-state error during tracking. Fig. $6 \mathrm{~b}$ shows the variation of the control signal variation to turbine governor valve. It can be seen that all the scheme spent similar control efforts in tracking the set-point. Table II shows that the value of PRMSE for the LQGI/LTR approaches is significantly lower than those of the other techniques. The control efforts in terms of $\mathcal{L}_{2} \mathrm{NI}$ and TVI are comparable for all the schemes in which the LQG takes the minimum value. The proposed technique gives a robust set-point tracking without much increment in control efforts.

\section{Pressurizer Loop}

The pressurizer control system consists of pressure and a level controller. The pressure control system controls the coolant pressure and maintains it within permissible limits. It is usually achieved by actuating a bank of heaters and by adjusting the spray flow rate.

1) Pressure Control by Heater: The performance of the proposed controller in tracking a set-point change in the pressurizer pressure using the heater system is shown in Fig. 


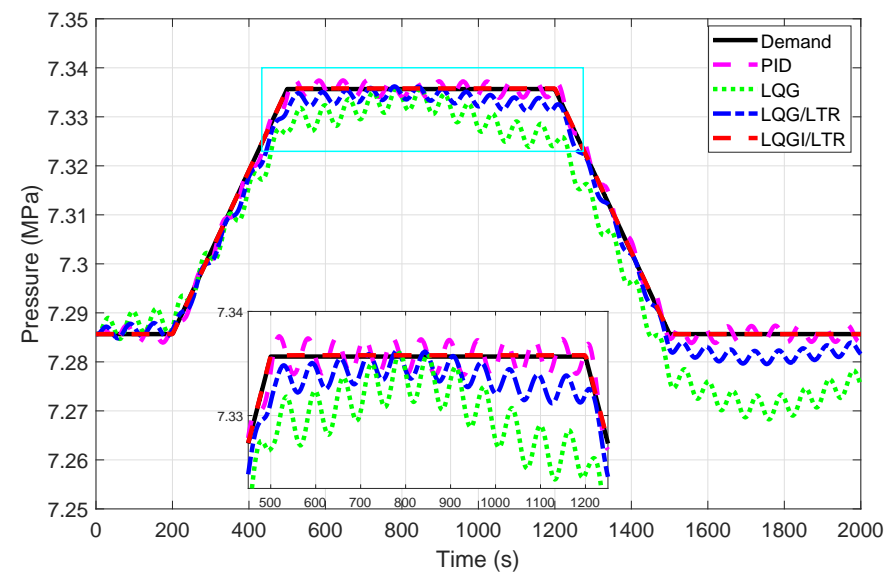

(a) Steam generator secondary pressure.

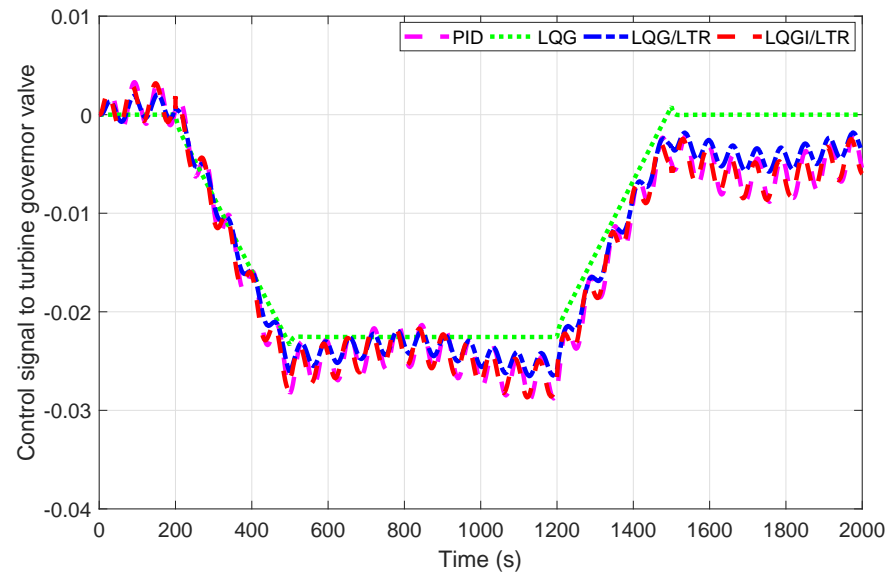

(b) Control signal to turbine governor valve.

Fig. 6: Variation of output and input signals during a set-point change in steam generator pressure.

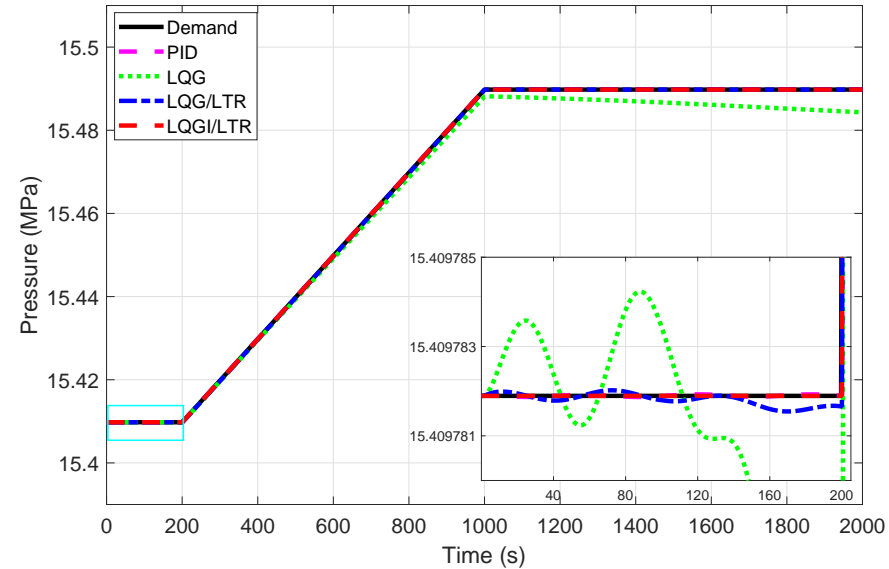

(a) Pressurizer pressure.

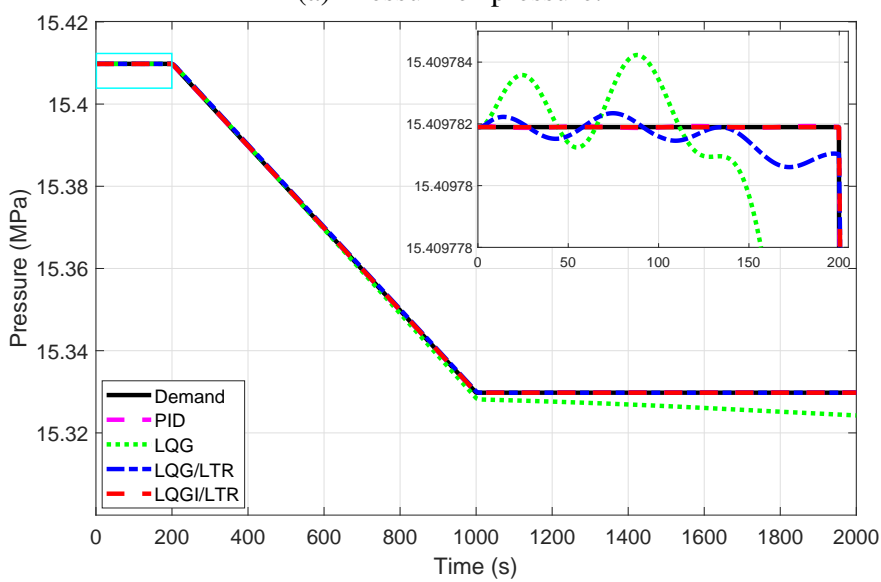

(c) Pressurizer pressure.

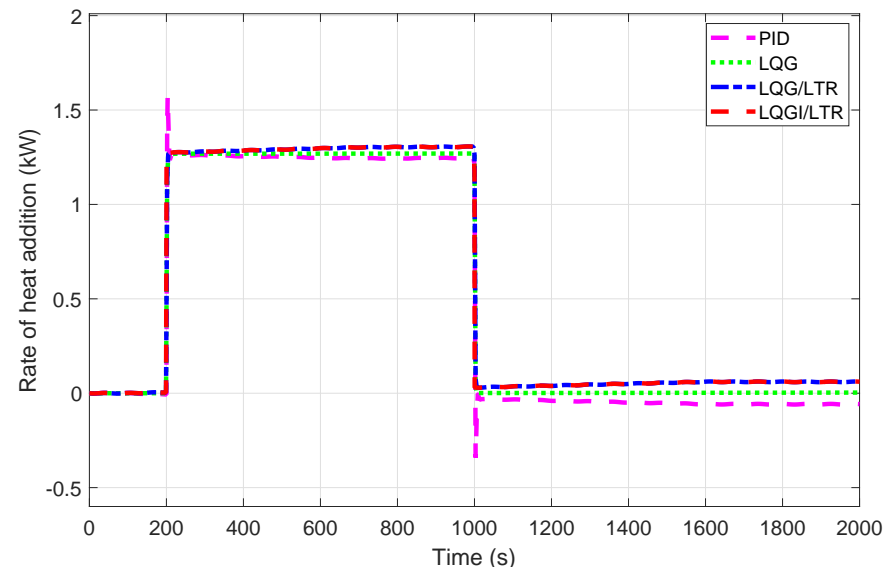

(b) Rate of heat addition.

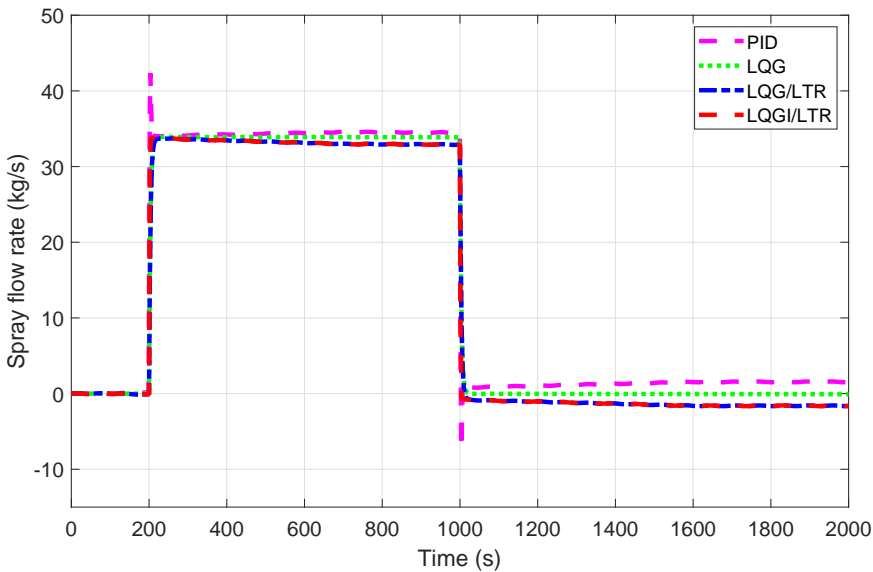

(d) Rate of spray flow.

Fig. 7: Variation of output and input signals during set-point change in pressurizer pressure.

7a. The following set-point variation is applied: Initially, for $200 \mathrm{~s}$, the pressure is maintained at a steady-state value of 15.41 MPa; then, it is changed to $15.49 \mathrm{MPa}$ in $800 \mathrm{~s}$ and held at $15.49 \mathrm{MPa}$ for the rest of the duration. It is observed that the LQG controller is unable to track the variation in the presence of uncertainties and disturbances and produces a large steady-state error. The PID, LQG/LTR, and LQGI/LTR controllers can track the variation. The LQGI/LTR controller gives better tracking and can handle system uncertainties and disturbances as compared to other approaches. Fig. $7 \mathrm{~b}$ shows the variation of the rate of heat addition. It can be observed that the PID scheme gives a sharp overshoot and undershoot in 
the control signal, whereas, other schemes give similar control variation control. Table II shows that the value of PRMSE for the LQGI/LTR approaches is lower than those of the other techniques. All the schemes take similar control efforts in terms of $\mathcal{L}_{2} \mathrm{NI}$ and TVI in which the LQG takes the minimum value.

2) Pressure Control by Spray: The performance of the proposed controller in tracking a set-point change in the pressurizer pressure using a spray system is shown in Fig. 7c. The following set-point variation is applied: Initially, for 200 $\mathrm{s}$, the pressure is maintained at a steady-state value of 15.41 $\mathrm{MPa}$; then, it is changed to $15.33 \mathrm{MPa}$ in $800 \mathrm{~s}$ and held at 15.33 $\mathrm{MPa}$ for rest of the duration. It can be seen that the LQG controller is unable to track the variation and produces a large steady-state error. The PID, LQG/LTR, and LQGI/LTR controllers can track the variations. The LQGI/LTR controller gives better set-point tracking and can handle system uncertainties and disturbances as compared to other approaches. The rate of spray flow is shown in Fig. 7d. The control performance is shown in Table II, which indicates that the value of PRMSE for the LQGI/LTR approach is significantly lower than those of the other techniques. All the schemes take similar control efforts in terms of $\mathcal{L}_{2} \mathrm{NI}$ and TVI. The LQG/LTR takes the minimum value of control energy, whereas the LQG gives a comparably smoother control signal.

3) Level Control: The purpose of a level control system in the pressurizer is to maintain the water level for the reactor core coolant system. A set-point change in pressurizer level is applied as follows: Initially, for $200 \mathrm{~s}$, the pressurizer level is maintained at a steady-state value of $28.06 \mathrm{~m}$; then, it is reduced to $26.56 \mathrm{~m}$ in $300 \mathrm{~s}$; held at 26.56 for $700 \mathrm{~s}$; then, it is increased to its initial value in $300 \mathrm{~s}$ and held at 28.06 $\mathrm{MPa}$ for the rest of the simulation. The performance of the proposed controller for tracking a set-point change in the pressurizer level is shown in Fig. 8a. It can be observed that the LQG controller is unable to track the variation in the presence of uncertainties and disturbances and produces a large steady-state error. The PID, LQG/LTR, and LQGI/LTR controllers can track the set-point variations, but, the PID and LQG/LTR controllers are unable to reject the disturbances. The control signal variation to the CVCS system is shown in Fig. $8 \mathrm{~b}$. It can be seen that the control effort associated with the different schemes is similar. The PID controller produces a sharp overshoot and undershoot. From Table II, it is noted that the value of PRMSE for the LQGI/LTR technique is significantly lower than those of the other techniques. All the schemes take similar control efforts in terms of $\mathcal{L}_{2} \mathrm{NI}$ and TVI in which the LQG takes the minimum control efforts and gives a comparably smoother control signal.

\section{Turbine Speed Loop}

The turbine speed control system regulates the shaft speed by controlling the steam flow to the turbine through the turbine governor valve. The performance of the proposed technique is tested in regulating the demand power using turbine speed. The demand power from the generator is changed as follows: Initially, for $180 \mathrm{~s}$, the demand power is maintained at $1 \mathrm{FFP}$; then, it is changed to $0.8 \mathrm{FFP}$ in $120 \mathrm{~s}$ at $10 \% / \mathrm{min}$; held at $0.8 \mathrm{FFP}$ for $680 \mathrm{~s}$; then, it is increased to $0.9 \mathrm{FFP}$ in $120 \mathrm{~s}$ at $5 \% / \mathrm{min}$; and held at $0.9 \mathrm{FFP}$ for $380 \mathrm{~s}$; then, it is changed to 1 FFP in $120 \mathrm{~s}$ held at 1 FFP for the rest of the duration. The performance of the proposed controller for tracking the variation in demand power is shown in Fig. 9a. The PID controller tracks the variation with $3.4 \%$ peak overshoot. Other schemes can track the variation smoothly in which the LQG controller tracks it very slowly. The control signal variation to turbine governor valve is shown in Fig. 9b. From Table II, it is observed that the value of PRMSE for the PID approach is lower than those of the other techniques. All the schemes take similar control efforts in terms of $\mathcal{L}_{2} \mathrm{NI}$ and TVI in which the LQG takes the minimum control efforts and gives a comparably smoother control signal. Overall, the LQGI/LTR controller gives better set-point tracking without any overshoot and can handle system uncertainties and disturbances.

\section{E. Discussion}

Pressurized water-type nuclear power plants are complex nonlinear systems that exhibit significant uncertainties in their dynamic response. Various uncertainties and disturbances, such as a sudden variation in rod position or speed, changes in valve opening, perturbation in feed-water inlet temperature, variation in pressurizer heater input or spray flow rate arise during the operation of a nuclear power plant. Besides, notable variations in core-neutronic and thermal-hydraulic parameters occur at different operating power levels in addition to variations in actuators and sensors signals due to mechanical and electrical equipment. Robust control techniques can effectively resist the impact of these adverse factors on the nuclear power plant and improve their operability and economy. These issues make the proposed robust-control technique, a timely, meaningful, and forward-looking step for the effective fault-tolerant control of nuclear power plants. Given the development in control theory and computer control hardware over the last few decades, many of the older but still operational PWR plants are upgrading their conventional control and instrumentation systems using computer-based automation [51]. In the case of a new PWR plant, the designs incorporate fully integrated computer-control systems based on distributed control system architectures [51]. Verification, validation and testing is an imperative procedure for life-cycle analysis of safety-critical real-time systems [52]. In the last decade, the acceptance of user-friendly software, such as Matlab/Simulink and Dymola, has increased, which are displacing procedural languages, such as those used by programmable logic controllers, in the implementation of real-time control and protection systems. Modelbased design with automatic code generation has also been employed for rapid prototyping and is increasingly being used in mass production deployment of software algorithms [53]. In parallel with these advancements, the complexity of both new and existing nuclear power plants has grown as a result of increased safety requirements and reliability, and demands for higher performance in an uncertain environment. The need for nuclear power plants to operate in load-following mode has grown due to increasing load fluctuation and the higher 


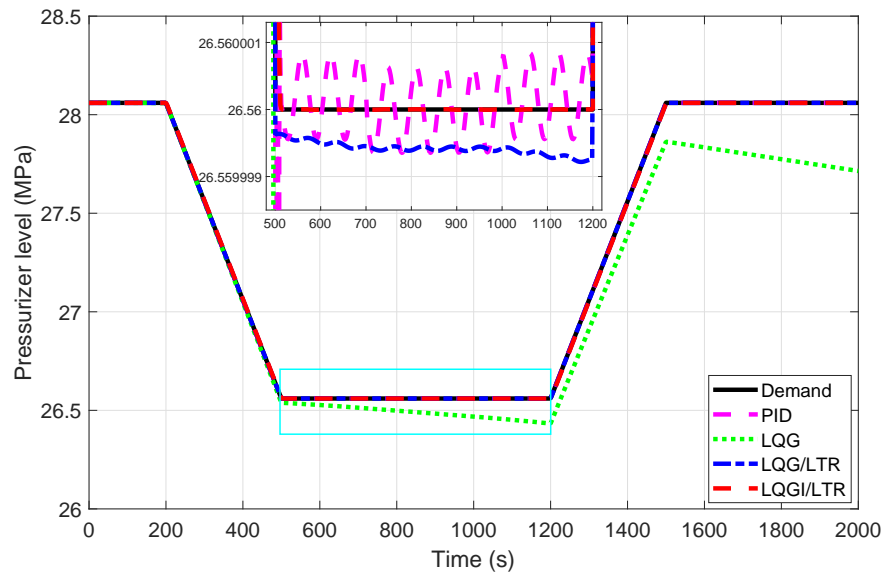

(a) Pressurizer level.

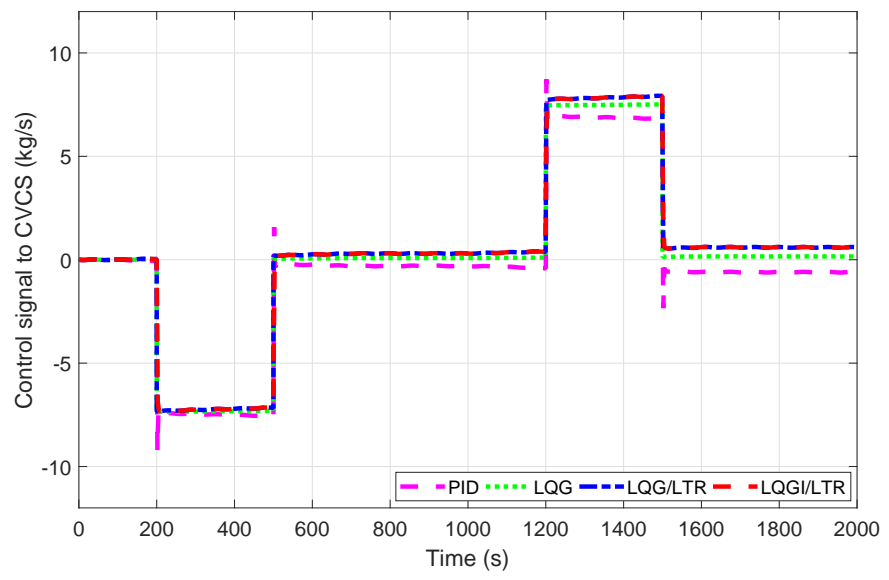

(b) Control signal to CVCS system.

Fig. 8: Variation of output and input signals during set-point change in pressurizer level.

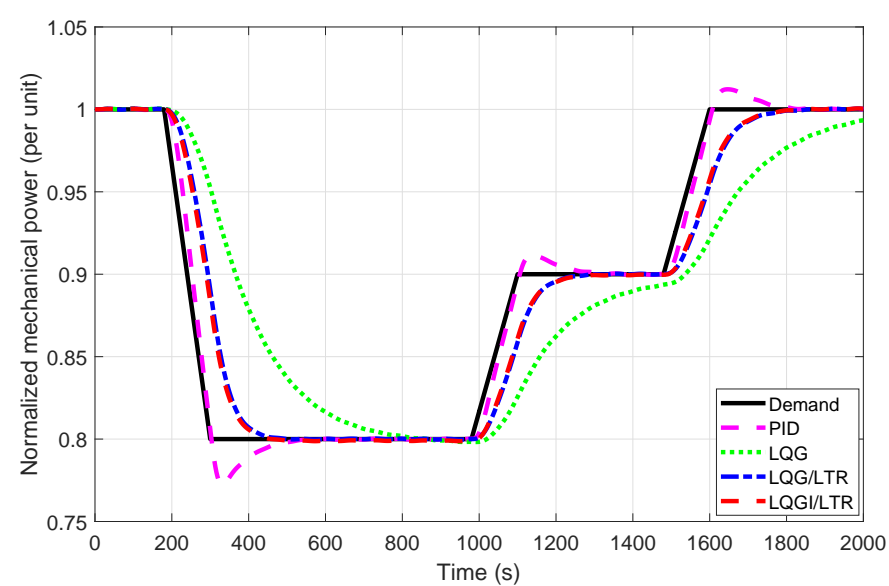

(a) Mechanical power.

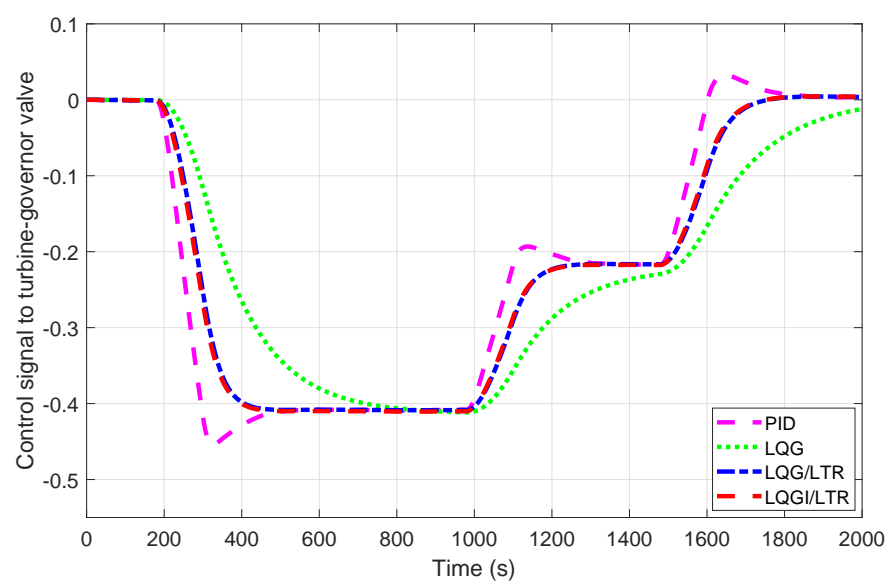

(b) Control signal to turbine governor valve.

Fig. 9: Variation of output and input signals during a demand change in mechanical power.

penetration of intermittent renewable energy in the power grid. Severe disturbances in frequency and voltage may seriously affect the availability and operability of a nuclear power plant. In this regard, the proposed robust control approach is found to be effective in handling the load-following mode of operation in the presence of parametric uncertainties and external disturbances of the ramp and sinusoidal types. The reactor control system allows the nuclear power plant to smoothly track typical load variations of $\pm 5 \% / \mathrm{min}$ and $\pm 10 \% / \mathrm{min}$ without any overshoot or undershoot in the controlled output. From the simulation results, it has been found that the proposed approach gives the least set-point tracking error in the presence of uncertainties and disturbances with similar control efforts as taken by PID [50], LQG [54], and LQG/LTR [38]. The proposed robust control approach acts as an output feedback controller alongside the state-feedback controller and shows improvement in the system performance and robustness with guaranteed tracking capabilities.

The nuclear power plant model employed in this work incorporates major plant dynamics to predict plant behaviour closely [46]. Due to its simple structure, the proposed control scheme can be straightforwardly implemented as a statefeedback control routine running on a digital control system. Nevertheless, the control technique should be verified (to check the correctness of hardware and software development steps) and validated (to assure the required performance and functionality) on engineering simulators before implementing it in actual plants following the relevant standards [55]. The main steps involved in control software verification and validation $(\mathrm{V} \& \mathrm{~V})$ includes verification of system requirements specification, computer system specification, software design, code, computer system integration, integrated computer system test, validation and commissioning test, system handover and acceptance, use and maintenance [55]. In the last few decades, due to the popularity and availability of open systems for hardware and software, the design of control and instrumentation by vendors follows international standards [51]. This makes possible the interoperability between disparate computing platforms and facilitates the deployment of new control software in different nuclear power plants. The proposed approach is likely to be well suited to other types of reactors as well with some modifications such as the definitions of input and output 
vectors and suitable tuning of controller parameters.

\section{CONCLusions}

Nuclear power plants are complex nonlinear systems that exhibit significant uncertainties in their dynamic behaviour. Thus, for their safe, stable, and efficient operation, it is necessary to design robust control techniques. In this paper, a new hybrid control strategy has been proposed by integrating the linear-quadratic integrator (LQI), linear-quadratic Gaussian (LQG), and loop transfer recovery (LTR) approaches for the control of a pressurized water reactor (PWR). The LQG control first designs the Kalman filter for state estimation and then employs the estimated states to enable a statefeedback control using the LQR design. The control law is then integrated with the LQI design to guarantee set-point tracking. Finally, the LTR technique ensures robustness in the presence of uncertainties. The overall control architecture thus yields a robust set-point tracking performance in an uncertain environment with zero steady-state error. The control performance of the proposed LQGI/LTR technique has been compared with the PID, LQG, and LQG/LTR control approaches. The effectiveness of all the control techniques has been validated using simulations on different subsections of the nonlinear PWR-type nuclear power plant model in the presence of parametric uncertainties and disturbances. Control strategies for the control of reactor power, coolant temperature, steam generator pressure, turbine speed, pressurizer pressure, and level have been designed and tested. For each loop, the control performances have been compared quantitatively using various numerical measures. The proposed controller has been found to work satisfactorily in the presence of disturbances and uncertainties with better set-point tracking over PID, LQG, and LQG/LTR controllers.

\section{ACKNOWLEDGEMENT}

The work presented in this paper has been financially supported under grants EP/R021961/1 and EP/R022062/1 from the Engineering and Physical Sciences Research Council.

\section{APPENDIX}

The parameters listed in Table A.1 correspond to a typical Westinghouse-type PWR. The parameters have been collected from the available literature on PWR-type plants [45], [47][49], Westinghouse documentation [56], and steam tables [57].

\section{NOMENCLATURE}

$A_{p} \quad$ Cross-sectional area of pressurizer $\left(m^{2}\right)$

$C_{i} \quad$ Delayed neutron precursor concentration (per unit)

$C_{t g} \quad$ Turbine governor valve coefficient

$G \quad$ Reactivity worth $(\Delta K / K)$

$H \quad$ Rate of rise of temperature $\left({ }^{0} \mathrm{Cs}^{-1}\right)$

I Moment of inertia $\left(\mathrm{kg} \cdot \mathrm{m}^{2}\right)$

$J \quad$ Conversion factor

$K \quad$ Gain

$P \quad$ Power (per unit)
TABLE II: Performance comparison of different control approaches

\begin{tabular}{|c|c|c|c|c|}
\hline Case & Technique & PRMSE & TVI & $\mathcal{L}_{2}$ NI \\
\hline \multirow{3}{*}{ A.1 } & PID & $2.207 \times 10^{-1}$ & $4.200 \times 10^{-2}$ & $2.278 \times 10^{0}$ \\
\cline { 2 - 5 } & LQG & $3.793 \times 10^{-1}$ & $2.460 \times 10^{-2}$ & $2.229 \times 10^{0}$ \\
\cline { 2 - 5 } & LQG/LTR & $1.723 \times 10^{0}$ & $2.210 \times 10^{-2}$ & $2.077 \times 10^{0}$ \\
\cline { 2 - 5 } & LQGI/LTR & $1.410 \times 10^{-2}$ & $4.260 \times 10^{-2}$ & $2.234 \times 10^{0}$ \\
\hline \hline \multirow{4}{*}{ A.2 } & PID & $6.697 \times 10^{1}$ & $2.940 \times 10^{-2}$ & $2.795 \times 10^{0}$ \\
\cline { 2 - 5 } & LQG & $1.067 \times 10^{2}$ & $2.570 \times 10^{-2}$ & $2.302 \times 10^{0}$ \\
\cline { 2 - 5 } & LQG/LTR & $7.299 \times 10^{1}$ & $2.960 \times 10^{-2}$ & $2.359 \times 10^{0}$ \\
\cline { 2 - 5 } & LQGI/LTR & $5.908 \times 10^{1}$ & $6.040 \times 10^{-2}$ & $2.451 \times 10^{0}$ \\
\hline \hline \multirow{4}{*}{ B } & PID & $1.257 \times 10^{-1}$ & $2.940 \times 10^{-1}$ & $2.443 \times 10^{1}$ \\
\cline { 2 - 5 } & LQG & $8.070 \times 10^{-1}$ & $5.297 \times 10^{-2}$ & $2.141 \times 10^{1}$ \\
\cline { 2 - 5 } & LQG/LTR & $2.723 \times 10^{-1}$ & $1.689 \times 10^{-1}$ & $2.331 \times 10^{1}$ \\
\cline { 2 - 5 } & LQGI/LTR & $8.916 \times 10^{-3}$ & $2.690 \times 10^{-1}$ & $2.449 \times 10^{1}$ \\
\hline \hline \multirow{3}{*}{.1} & PID & $6.324 \times 10^{-4}$ & $4.119 \times 10^{3}$ & $1.134 \times 10^{6}$ \\
\cline { 2 - 5 } & LQG & $2.559 \times 10^{-1}$ & $2.540 \times 10^{3}$ & $1.120 \times 10^{6}$ \\
\cline { 2 - 5 } & LQG/LTR & $5.654 \times 10^{-3}$ & $2.759 \times 10^{3}$ & $1.158 \times 10^{6}$ \\
\cline { 2 - 5 } & LQGI/LTR & $3.407 \times 10^{-4}$ & $2.761 \times 10^{3}$ & $1.158 \times 10^{6}$ \\
\hline \hline \multirow{3}{*}{ C.2 } & PID & $6.321 \times 10^{-3}$ & $1.094 \times 10^{2}$ & $3.080 \times 10^{4}$ \\
\cline { 2 - 5 } & LQG & $2.556 \times 10^{-1}$ & $6.789 \times 10^{1}$ & $3.024 \times 10^{4}$ \\
\cline { 2 - 5 } & LQG/LTR & $2.050 \times 10^{-2}$ & $7.279 \times 10^{1}$ & $2.967 \times 10^{4}$ \\
\cline { 2 - 5 } & LQGI/LTR & $3.388 \times 10^{-4}$ & $7.332 \times 10^{1}$ & $2.972 \times 10^{4}$ \\
\hline \hline \multirow{3}{*}{ C.3 } & PID & $9.274 \times 10^{-3}$ & $4.727 \times 10^{1}$ & $5.742 \times 10^{3}$ \\
\cline { 2 - 5 } & LQG & $1.574 \times 10^{1}$ & $2.983 \times 10^{1}$ & $5.596 \times 10^{3}$ \\
\cline { 2 - 5 } & LQG/LTR & $2.734 \times 10^{-1}$ & $3.163 \times 10^{1}$ & $5.861 \times 10^{3}$ \\
\cline { 2 - 5 } & LQGI/LTR & $8.066 \times 10^{-4}$ & $3.159 \times 10^{1}$ & $5.851 \times 10^{3}$ \\
\cline { 2 - 5 } & PID & $8.635 \times 10^{-1}$ & $1.036 \times 10^{0}$ & $3.946 \times 10^{2}$ \\
\cline { 2 - 5 } & LQG/LTR & $2.658 \times 10^{0}$ & $8.154 \times 10^{-1}$ & $3.775 \times 10^{2}$ \\
\cline { 2 - 5 } & LQGI/LTR & $2.163 \times 10^{0}$ & $8.286 \times 10^{-1}$ & $3.873 \times 10^{2}$ \\
\hline \hline & & & $3.890 \times 10^{2}$ \\
\hline
\end{tabular}

$\begin{array}{ll}Q_{\text {heat }} & \text { Rate of heat addition }(\mathrm{kW} / \mathrm{s}) \\ S & \text { Effective heat transfer area }\left(\mathrm{m}^{2}\right) \\ T & \text { Average temperature }\left({ }^{0} \mathrm{C}\right) \\ U & \text { Heat transfer coefficient }\left(\mathrm{W} / \mathrm{m}^{2} .{ }^{0} \mathrm{C}\right) \\ V & \text { Volume }\left(\mathrm{m}^{3}\right) \\ c_{p} & \text { Specific heat }\left(\mathrm{J} / \mathrm{kg} \cdot{ }^{0} \mathrm{C}\right) \\ d & \text { Density }\left(\mathrm{kg} / \mathrm{m}^{3}\right) \\ h & \text { Enthalpy }(\mathrm{J} / \mathrm{kg}) \\ i & \text { Current }(\mathrm{mA}) \\ l & \text { Pressurizer length }(\mathrm{m}) \\ m & \text { Mass }(\mathrm{kg}) \\ \dot{m} & \text { Mass flow rate }(\mathrm{kg} / \mathrm{s}) \\ p & \text { Pressure }(\mathrm{MPa}) \\ v_{\text {rod }} & \text { Rod speed }(\mathrm{m} / \mathrm{s}) \\ \Lambda & \text { Neutron generation time }(\mathrm{s}) \\ \alpha & \text { Coefficient of reactivity }\left({ }^{0} \mathrm{C}^{-1}\right) \\ \beta & \text { Fraction of delayed neutrons } \\ \kappa & \text { Constant } \\ \lambda & \text { Decay constant }\left(\mathrm{s}^{-1}\right) \\ \rho & \text { Reactivity }(\Delta \mathrm{K} / \mathrm{K}) \\ \zeta & \text { Damping ratio } \\ \tau & \text { Time constant }(\mathrm{s}) \\ \nu & \text { Specific volume }\left(\mathrm{m}^{3} / \mathrm{kg}\right) \\ \omega_{\text {tur }} & \text { Turbine speed }(\mathrm{rad} / \mathrm{s}) \\ \varpi & \text { Natural frequency of oscillation }(\mathrm{rad} / \mathrm{s}) \\ \text { Subscripts } & \end{array}$


TABLE A.1: Typical Parameters of a Westinghouse-type 1.2 GWe PWR Plant

\begin{tabular}{|c|c|c|c|c|c|}
\hline $\begin{array}{c}\lambda_{1}\left(s^{-1}\right) \\
1.2437 \times 10^{-2}\end{array}$ & $\begin{array}{c}\lambda_{2}\left(s^{-1}\right) \\
3.05 \times 10^{-2}\end{array}$ & $\begin{array}{c}\lambda_{3}\left(s^{-1}\right) \\
1.1141 \times 10^{-1}\end{array}$ & $\begin{array}{c}\lambda_{4}\left(s^{-1}\right) \\
3.013 \times 10^{-1}\end{array}$ & $\begin{array}{l}\lambda_{5}\left(s^{-1}\right) \\
1.12866\end{array}$ & $\begin{array}{c}\lambda_{6}\left(s^{-1}\right) \\
3.0130\end{array}$ \\
\hline $\begin{array}{c}\beta_{1} \\
2.15 \times 10^{-4}\end{array}$ & $\begin{array}{c}\beta_{2} \\
1.424 \times 10^{-3}\end{array}$ & $\begin{array}{c}\beta_{3} \\
1.274 \times 10^{-3}\end{array}$ & $\begin{array}{c}\beta_{4} \\
2.568 \times 10^{-3}\end{array}$ & $\begin{array}{c}\beta_{5} \\
7.48 \times 10^{-4}\end{array}$ & $\begin{array}{c}\beta_{6} \\
2.73 \times 10^{-4}\end{array}$ \\
\hline $\begin{array}{c}\Lambda(s) \\
3 \times 10^{-5}\end{array}$ & $\begin{array}{c}H_{f}\left({ }^{0} \mathrm{Cs}^{-1}\right) \\
71.8725\end{array}$ & $\begin{array}{c}H_{c}\left({ }^{0} \mathrm{Cs}^{-1}\right) \\
1.1254\end{array}$ & $\begin{array}{l}\tau_{f}(s) \\
4.376\end{array}$ & $\begin{array}{c}\tau_{c}(s) \\
10.893\end{array}$ & $\begin{array}{l}\tau_{r}(s) \\
0.703\end{array}$ \\
\hline $\begin{array}{c}\tau_{r x u}(s) \\
2.517\end{array}$ & $\begin{array}{c}\tau_{r x i}(s) \\
2.145\end{array}$ & $\begin{array}{c}\tau_{\text {hot }}(s) \\
0.234\end{array}$ & $\begin{array}{c}\tau_{\text {cold }}(s) \\
1.310\end{array}$ & $\begin{array}{c}\tau_{s g u}(s) \\
0.726\end{array}$ & $\begin{array}{c}\tau_{s g i}(s) \\
0.659\end{array}$ \\
\hline $\begin{array}{l}\tau_{p 1}(s) \\
1.2815\end{array}$ & $\begin{array}{l}\tau_{p 2}(s) \\
1.2815\end{array}$ & $\begin{array}{c}\tau_{p m 1}(s) \\
0.5826 \\
\end{array}$ & $\begin{array}{c}\tau_{p m 2}(s) \\
0.5826 \\
\end{array}$ & $\begin{array}{c}\tau_{m p 1}(s) \\
0.3519 \\
\end{array}$ & $\begin{array}{c}\tau_{m p 2}(s) \\
0.1676 \\
\end{array}$ \\
\hline $\begin{array}{c}\tau_{m s 1}(s) \\
0.3519\end{array}$ & $\begin{array}{r}\tau_{m s 2}(s) \\
0.1676\end{array}$ & $\begin{array}{c}U_{m s 1} S_{m s 1}\left(W^{0} C^{-1}\right) \\
1.7295 \times 10^{8}\end{array}$ & $\begin{array}{c}U_{m s 2} S_{m s 2}\left(W^{0} C^{-1}\right) \\
3.6312 \times 10^{8}\end{array}$ & $\begin{array}{c}c_{p f w}\left(\mathrm{~J} / \mathrm{kg} \cdot{ }^{0} \mathrm{C}\right) \\
5.4791 \times 10^{3}\end{array}$ & $\begin{array}{c}C_{t g} \\
2.0481\end{array}$ \\
\hline$\frac{\partial T_{\text {sat }}}{\partial p_{s}}\left({ }^{0} \mathrm{C} / \mathrm{MPa}\right)$ & $h_{s s}(J / k g)$ & $K_{s}(J / M P a)$ & $m_{s}(k g)$ & $m_{w}(k g)$ & $d_{w}\left(k g / m^{3}\right)$ \\
\hline 9.47 & $2.7656 \times 10^{6}$ & $8.1016 \times 10^{7}$ & $2.0518 \times 10^{3}$ & $1.8167 \times 10^{4}$ & 595.6684 \\
\hline $\begin{array}{c}d_{s}\left(\mathrm{~kg} / \mathrm{m}^{3}\right) \\
100.9506\end{array}$ & $\begin{array}{l}V_{w}\left(m^{3}\right) \\
30.4988\end{array}$ & $\begin{array}{c}A_{p}\left(m^{2}\right) \\
3.566\end{array}$ & $\begin{array}{c}l(m) \\
14.2524\end{array}$ & $\begin{array}{c}G(\Delta K / K) \\
14.5 \times 10^{-3}\end{array}$ & $\begin{array}{l}\dot{m}_{\text {sor }}(\mathrm{kg} / \mathrm{s}) \\
2.1642 \times 10^{3}\end{array}$ \\
\hline$h_{\text {spr }}(\mathrm{J} / \mathrm{kg})$ & $h_{w}(J / k g)$ & $h_{\bar{w}}(J / k g)$ & $\nu_{w}\left(m^{3} / k g\right)$ & $\nu_{s}\left(m^{3} / k g\right)$ & $J_{p}$ \\
\hline $1.336 \times 10^{6}$ & $1.6266 \times 10^{6}$ & $9.7209 \times 10^{5}$ & $1.7 \times 10^{-3}$ & $9.9 \times 10^{-3}$ & 5.4027 \\
\hline $\begin{array}{c}V_{1} \vartheta_{1}\left(\mathrm{~kg} /{ }^{0} \mathrm{C}\right) \\
0.5991\end{array}$ & $\begin{array}{c}V_{2} \vartheta_{2}\left(\mathrm{~kg} /{ }^{0} \mathrm{C}\right) \\
0.1814\end{array}$ & $\begin{array}{c}V_{3} \vartheta_{3}\left(\mathrm{~kg} /{ }^{0} \mathrm{C}\right) \\
0.1814\end{array}$ & $\begin{array}{c}V_{4} \vartheta_{4}\left(\mathrm{~kg} /{ }^{0} \mathrm{C}\right) \\
1.3164\end{array}$ & $\begin{array}{c}V_{5} \vartheta_{5}\left(\mathrm{~kg} /{ }^{0} \mathrm{C}\right) \\
0.2752\end{array}$ & $\begin{array}{c}V_{6} \vartheta_{6}\left(\mathrm{~kg} /{ }^{0} \mathrm{C}\right) \\
2.776\end{array}$ \\
\hline$V_{7} \vartheta_{7}\left(\mathrm{~kg} /{ }^{0} \mathrm{C}\right)$ & $V_{8} \vartheta_{8}\left(k g /{ }^{0} \mathrm{C}\right)$ & $V_{9} \vartheta_{9}\left(\mathrm{~kg} /{ }^{0} \mathrm{C}\right)$ & $V_{10} \vartheta_{10}\left(\mathrm{~kg} /{ }^{0} \mathrm{C}\right)$ & $K_{1 p}\left(\mathrm{~kg} / \mathrm{m}^{3} \cdot M P a\right)$ & $K_{2 p}\left(\mathrm{~kg} / \mathrm{m}^{3} \cdot M P a\right)$ \\
\hline 0.6022 & 0.6022 & 0.2776 & 0.1927 & $-8.152 \times 10^{-3}$ & $4.708 \times 10^{-3}$ \\
\hline $\begin{array}{c}K_{3 p}\left(\mathrm{~J} / \mathrm{m}^{3} \cdot M P a\right) \\
-1.118 \times 10^{-4}\end{array}$ & $\begin{array}{c}K_{4 p}\left(m^{3} / \mathrm{kg} \cdot M P a\right) \\
4.708 \times 10^{-3}\end{array}$ & $\begin{array}{l}F_{h p} \\
0.33\end{array}$ & $\begin{array}{c}F_{i p} \\
0\end{array}$ & $\begin{array}{l}F_{l p} \\
0.67\end{array}$ & $\begin{array}{l}O_{r v} \\
1.0\end{array}$ \\
\hline $\begin{array}{c}\tau_{h p}(s) \\
10.0\end{array}$ & $\begin{array}{c}\tau_{i p}(s) \\
0.4\end{array}$ & $\begin{array}{c}\tau_{l p}(s) \\
1.0\end{array}$ & $\begin{array}{l}\kappa_{h p} \\
0.8\end{array}$ & $\begin{array}{c}J_{\text {tur }} \\
5.4040\end{array}$ & $\begin{array}{c}I_{t g}\left(\mathrm{~kg} \cdot \mathrm{m}^{2}\right) \\
1.99642 \times 10^{5}\end{array}$ \\
\hline $\begin{array}{c}\alpha_{f}\left(\Delta K / K /{ }^{0} C\right) \\
-2.16 \times 10^{-5}\end{array}$ & $\begin{array}{c}\alpha_{c}\left(\Delta K / K /{ }^{0} C\right) \\
-1.8 \times 10^{-4}\end{array}$ & $\begin{array}{c}\alpha_{p}(\Delta K / K / M P a) \\
1.5664 \times 10^{-4}\end{array}$ & $\begin{array}{c}\tau_{1}(s) \\
5 \times 10^{-8}\end{array}$ & $\begin{array}{c}\tau_{2}(s) \\
2 \times 10^{-3}\end{array}$ & $\begin{array}{c}K_{l o}(m A) \\
1.9569\end{array}$ \\
\hline $\begin{array}{c}\kappa_{l o} \\
1.1067 \times 10^{10}\end{array}$ & $\begin{array}{c}\tau_{r t d}(s) \\
8.2\end{array}$ & $\begin{array}{c}K_{r t d}(m A) \\
10.667\end{array}$ & $\begin{array}{c}K_{t g}\left(m A^{-1}\right) \\
6.25 \\
\end{array}$ & $\begin{array}{c}\zeta_{t g} \\
0.4933\end{array}$ & $\begin{array}{c}\varpi_{t g}(\mathrm{rad} / \mathrm{s}) \\
14.6253\end{array}$ \\
\hline $\begin{array}{c}P(G W e) \\
1.2\end{array}$ & $\begin{array}{c}T_{f 0}\left({ }^{0} \mathrm{C}\right) \\
626.66 \\
\end{array}$ & $\begin{array}{c}T_{c 10}\left({ }^{0} \mathrm{C}\right) \\
312.13\end{array}$ & $\begin{array}{c}T_{c 20}\left({ }^{0} C\right) \\
327.30\end{array}$ & $\begin{array}{c}T_{\text {rxu0 }}\left({ }^{0} C\right) \\
327.30\end{array}$ & $\begin{array}{c}T_{\text {hot } 0}\left({ }^{0} \mathrm{C}\right) \\
327.30\end{array}$ \\
\hline $\begin{array}{c}T_{\text {sgi0 }}\left({ }^{0} C\right) \\
327.30 \\
\end{array}$ & $\begin{array}{c}T_{\text {sgu } 0}\left({ }^{0} \mathrm{C}\right) \\
296.96 \\
\end{array}$ & $\begin{array}{c}T_{\text {cold } 0}\left({ }^{0} C\right) \\
296.96\end{array}$ & $\begin{array}{c}T_{r x i 0}\left({ }^{0} \mathrm{C}\right) \\
296.96 \\
\end{array}$ & $\begin{array}{c}T_{p 10}\left({ }^{0} C\right) \\
306.75 \\
\end{array}$ & $\begin{array}{c}T_{p 20}\left({ }^{0} C\right) \\
296.96 \\
\end{array}$ \\
\hline $\begin{array}{c}T_{m 10}\left({ }^{\circ} C\right) \\
297.41\end{array}$ & $\begin{array}{c}T_{m 20}\left({ }^{\circ} C\right) \\
292.51\end{array}$ & $\begin{array}{c}T_{s 0}\left({ }^{0} \mathrm{C}\right) \\
288.06\end{array}$ & $\begin{array}{c}p_{s 0}(M P a) \\
7.28\end{array}$ & $\begin{array}{c}p_{p 0}(M P a) \\
15.41\end{array}$ & $\begin{array}{c}l_{w 0}(m) \\
28.06\end{array}$ \\
\hline $\begin{array}{c}T_{r t d 10}\left({ }^{0} C\right) \\
327.30\end{array}$ & $\begin{array}{c}T_{r t d 20}\left({ }^{0} C\right) \\
327.30\end{array}$ & $\begin{array}{c}T_{f w}\left({ }^{0} \mathrm{C}\right) \\
232.20\end{array}$ & $\begin{array}{c}i_{l o 0}(m A) \\
19.65\end{array}$ & $\begin{array}{c}i_{r t d 0}(m A) \\
14.66\end{array}$ & $\begin{array}{c}\omega_{\text {tur } 0}(\mathrm{rad} / \mathrm{s}) \\
360\end{array}$ \\
\hline
\end{tabular}

$c 1, c 2$

dem

$f$

$f w$

hot, cold

$h p, i p, l p$,

lo

$m 1, m 2$

$m p 1, m p 2$

$m s 1, m s 2$

$n$

$p$

$p 1, p 2$

pm1, pm2
Coolant at node 1 and 2

Demand

Fuel

Feed-water

Hot-leg and cold-leg

High pressure, intermediate pressure, and low pressure

$i^{t h}$ group of delayed neutron precursor

Logarithmic amplifier

MTL 1 and MTL 2

Transfer from MTL 1 to PCL 1 and MTL

2 to PCL 2

Transfer from MTL 1 and 2 to SCL

Normalized values

Pressurizer

PCL 1 and PCL 2

Transfer from PCL 1 to MTL 1 and PCL 2

to MTL 2 rod

$r x i, r x u$

$s, s s$

$s g, s g i, s g u$

spr, sur

rtd1, rtd2

$t g$

tur

$w, w s$
Regulating rod

Reactor lower plenum and reactor upper plenum

Steam and steam in secondary

Steam generator, steam generator inlet, and steam generator outlet

Spray and surge

RTD 1 and 2

Turbine-Governor

Turbine

Water and water in secondary 


\section{REFERENCES}

[1] K. Suzuki, J. Shimazaki, and Y. Shinohara, "Application of $\mathrm{H} \infty$ control theory to power control of a nonlinear reactor model," Nuclear Science and Engineering, vol. 115, no. 2, pp. 142-151, 1993.

[2] S. G. Chi and N. Z. Cho, "H $\infty$ control theory applied to xenon control for load-following operation of a nuclear reactor," Nuclear Technology, vol. 137, no. 2, pp. 127-138, 2002.

[3] H. M. Emara, A. A. Hanafy, M. M. Z. Abdelaal, and S. Elaraby, "A novel, robust control methodology application to nuclear reactors," Nuclear Science and Engineering, vol. 174, no. 1, pp. 87-95, 2013.

[4] G. Li, B. Liang, X. Wang, and X. Li, "Multivariable modeling and nonlinear coordination control of nuclear reactor cores with/without xenon oscillation using $\mathrm{H} \infty$ loop shaping approach," Annals of Nuclear Energy, vol. 111, pp. 82 - 100, 2018.

[5] X. Yan, P. Wang, J. Qing, S. Wu, and F. Zhao, "Robust power control design for a small pressurized water reactor using an $\mathrm{H}$ infinity mixed sensitivity method," Nuclear Engineering and Technology, 2020.

[6] A. Etchepareborda and J. Lolich, "Research reactor power controller design using an output feedback nonlinear receding horizon control method," Nuclear Engineering and Design, vol. 237, no. 3, pp. 268 - 276, 2007.

[7] M. G. Na, I. J. Hwang, and Y. J. Lee, "Design of a fuzzy model predictive power controller for pressurized water reactors," IEEE Transactions on Nuclear Science, vol. 53, no. 3, pp. 1504-1514, 2006.

[8] H. Eliasi, M. B. Menhaj, and H. Davilu, "Robust nonlinear model predictive control for nuclear power plants in load following operations with bounded xenon oscillations," Nuclear Engineering and Design, vol. 241, pp. 533-543, 2011.

[9] — , "Robust nonlinear model predictive control for a PWR nuclear power plant," Progress in Nuclear Energy, vol. 54, pp. 177-185, 2012.

[10] V. Vajpayee, S. Mukhopadhyay, and A. P. Tiwari, "Subspace-based wavelet preprocessed data-driven predictive control," INCOSE International Symposium, vol. 26, no. s1, pp. 357-371, 2016.

[11] — "Data-driven subspace predictive control of a nuclear reactor," IEEE Transactions on Nuclear Science, vol. 65, no. 2, pp. 666-679, Feb 2018.

[12] V. Vajpayee, V. Becerra, N. Bausch, S. Banerjee, J. Deng, S. R. Shimjith, and A. J. Arul, "Gain scheduled subspace predictive control of a pressurized water-type nuclear reactor," in 2020 28th Mediterranean Conference on Control and Automation (MED), 2020, pp. 91-96.

[13] V. Vajpayee, V. Becerra, N. Bausch, S. Banerjee, J. Deng, S. R Shimjith, and A. John Arul, "Disturbance observer-based subspace predictive control of a pressurized water-type nuclear reactor," in 2020 7th International Conference on Control, Decision and Information Technologies (CoDIT), vol. 1, 2020, pp. 1012-1017.

[14] —, "Robust subspace predictive control based on integral sliding mode for a pressurized water reactor," in 2020 7th International Conference on Control, Decision and Information Technologies (CoDIT), vol. 1, 2020, pp. 7-12.

[15] G. Ansarifar and H. Akhavan, "Sliding mode control design for a PWR nuclear reactor using sliding mode observer during load following operation," Annals of Nuclear Energy, vol. 75, pp. 611 - 619, 2015.

[16] G. D. Reddy, B. Bandyopadhyay, and A. P. Tiwari, "Multirate output feedback based sliding mode spatial control for a large PHWR," IEEE Transactions on Nuclear Science, vol. 54, no. 6, pp. 2677-2686, 2007.

[17] R. K. Munje, B. M. Patre, S. R. Shimjith, and A. P. Tiwari, "Sliding mode control for spatial stabilization of advanced heavy water reactor," IEEE Transactions on Nuclear Science, vol. 60, no. 4, pp. 3040-3050, 2013.

[18] R. J. Desai, B. M. Patre, R. K. Munje, A. P. Tiwari, and S. R. Shimjith, "Integral sliding mode for power distribution control of advanced heavy water reactor," IEEE Transactions on Nuclear Science, pp. 1-1, 2020.

[19] P. V. Surjagade, A. P. Tiwari, and S. R. Shimjith, "Robust optimal integral sliding mode controller for total power control of large phwrs," IEEE Transactions on Nuclear Science, vol. 65, no. 7, pp. 1331-1344, 2018.

[20] V. Vajpayee, V. Becerra, N. Bausch, J. Deng, S. Shimjith, and A. J. Arul, "Robust-optimal integrated control design technique for a pressurized water-type nuclear power plant," Progress in Nuclear Energy, p. 103575, 2020.

[21] S. Banerjee, K. Halder, S. Dasgupta, S. Mukhopadhyay, K. Ghosh, and A. Gupta, "An interval approach for robust control of a large PHWR with PID controllers," IEEE Transactions on Nuclear Science, vol. 62, no. 1, pp. 281-292, 2015.
[22] S. Das, S. Das, and A. Gupta, "Fractional order modeling of a PHWR under step-back condition and control of its global power with a robust $P I^{\lambda} D^{\mu}$ controller," IEEE Transactions on Nuclear Science, vol. 58, no. 5, pp. 2431-2441, 2011.

[23] S. Bhase and B. Patre, "Robust FOPI controller design for power control of PHWR under step-back condition," Nuclear Engineering and Design, vol. 274 , pp. $20-29,2014$.

[24] M. N. Khajavi, M. B. Menhaj, and A. A. Suratgar, "A neural network controller for load following operation of nuclear reactors," Annals of Nuclear Energy, vol. 29, no. 6, pp. 751 - 760, 2002.

[25] M. Boroushaki, M. B. Ghofrani, C. Lucas, and M. J. Yazdanpanah, "An intelligent nuclear reactor core controller for load following operations, using recurrent neural networks and fuzzy systems," Annals of Nuclear Energy, vol. 30, no. 1, pp. 63 - 80, 2003.

[26] S. S. Khorramabadi, M. Boroushaki, and C. Lucas, "Emotional learning based intelligent controller for a PWR nuclear reactor core during load following operation," Annals of Nuclear Energy, vol. 35, no. 11, pp. 2051 - 2058, 2008.

[27] C. Liu, J.-F. Peng, F.-Y. Zhao, and C. Li, "Design and optimization of fuzzy-PID controller for the nuclear reactor power control," Nuclear Engineering and Design, vol. 239, no. 11, pp. 2311 - 2316, 2009.

[28] P. S. Londhe, B. M. Patre, and A. P. Tiwari, "Fuzzy-like PD controller for spatial control of advanced heavy water reactor," Nuclear Engineering and Design, vol. 274, pp. 77 - 89, 2014

[29] M. Eom, D. Chwa, and D. Baang, "Robust disturbance observer-based feedback linearization control for a research reactor considering a power change rate constraint," IEEE Transactions on Nuclear Science, vol. 62, no. 3, pp. 1301-1312, 2015.

[30] S. M. H. Mousakazemi, N. Ayoobian, and G. R. Ansarifar, "Control of the reactor core power in PWR using optimized PID controller with the real-coded GA," Annals of Nuclear Energy, vol. 118, pp. 107 - 121, 2018.

[31] R. M. Edwards, K. Y. Lee, and M. A. Schultz, "State feedback assisted classical control: An incremental approach to control modernization of existing and future nuclear reactors and power plants," Nuclear Technology, vol. 92, no. 2, pp. 167-185, 1990.

[32] R. M. Edwards, K. Y. Lee, and A. Ray, "Robust optimal control of nuclear reactors and power plants," Nuclear Technology, vol. 98, no. 2, pp. 137-148, 1992

[33] R. Shaffer, W. He, and R. M. Edwards, "Design and validation of optimized feedforward with robust feedback control of a nuclear reactor," Nuclear Technology, vol. 147, no. 2, pp. 240-257, 2004.

[34] M. Athans, "A tutorial on the LQG/LTR method," in 1986 American Control Conference, 1986, pp. 1289-1296.

[35] J. Doyle and G. Stein, "Multivariable feedback design: Concepts for a classical/modern synthesis," IEEE Transactions on Automatic Control, vol. 26, no. 1, pp. 4-16, 1981.

[36] A. Ben-Abdennour, K. Y. Lee, and R. M. Edwards, "Multivariable robust control of a power plant deaerator," IEEE Transactions on Energy Conversion, vol. 8, no. 1, pp. 123-129, 1993.

[37] A. Ben-Abdennour, R. M. Edwards, and K. Y. Lee, "LQG/LTR robust control of nuclear reactors with improved temperature performance," IEEE Transactions on Nuclear Science, vol. 39, no. 6, pp. 2286-2294, 1992.

[38] H. Arab-Alibeik and S. Setayeshi, "Improved temperature control of a PWR nuclear reactor using an LQG/LTR based controller,' IEEE Transactions on Nuclear Science, vol. 50, pp. 211-218, 2003.

[39] G. Li, "Modeling and LQG/LTR control for power and axial power difference of load-follow PWR core," Annals of Nuclear Energy, vol. 68, pp. 193 - 203, 2014

[40] G. Li and F. Zhao, "Flexibility control and simulation with multi-model and LQG/LTR design for pwr core load following operation," Annals of Nuclear Energy, vol. 56, pp. 179 - 188, 2013.

[41] J. Wan and P. Wang, "LQG/LTR controller design based on improved SFACC for the PWR reactor power control system," Nuclear Science and Engineering, vol. 194, no. 6, pp. 433-446, 2020.

[42] F. Huerta, D. Pizarro, S. Cobreces, F. J. Rodriguez, C. Giron, and A. Rodriguez, "LQG servo controller for the current control of LCL gridconnected voltage-source converters," IEEE Transactions on Industrial Electronics, vol. 59, no. 11, pp. 4272-4284, 2012.

[43] T. Hagiwara, E. Furutani, and M. Araki, "Optimal observers for disturbance rejection in two-degree-of-freedom LQI servo systems," IEE Proceedings - Control Theory and Applications, vol. 144, no. 6, pp. 575-581, 1997.

[44] E. Furutani, T. Hagiwara, and M. Araki, "Two-degree-of-freedom design method of state-predictive LQI servo systems," IEE Proceedings Control Theory and Applications, vol. 149, no. 5, pp. 365-378, 2002. 
[45] L. Wang, W. Sun, J. Zhao, and D. Liu, "A speed-governing system model with over-frequency protection for nuclear power generating units," Energies, vol. 13, no. 173, 2020.

[46] V. Vajpayee, V. Becerra, N. Bausch, J. Deng, S. R. Shimjith, and A. J. Arul, "Dynamic modelling, simulation, and control design of a pressurized water-type nuclear power plant," Nuclear Engineering and Design, vol. 370, p. 110901, 2020.

[47] T. W. Kerlin, Dynamic Analysis and Control of Pressurized Water Reactors. Academic Press, 1978, vol. 14.

[48] M. R. A. Ali, Lumped Parameter, State Variable Dynamic Models for Utube Recirculation Type Nuclear Steam Generators. PhD dissertation, University of Tennessee, Knoxville, 1976.

[49] M. Naghedolfeizi, Dynamic Modeling of a Pressurized Water Reactor Plant for Diagnostics and Control. Master's thesis, University of Tennessee, Knoxville, 1990.

[50] C. S. Subudhi, T. U. Bhatt, and A. P. Tiwari, "A mathematical model for total power control loop of large PHWRs," IEEE Transactions on Nuclear Science, vol. 63, no. 3, pp. 1901-1911, June 2016.

[51] Modern Instrumentation and Control for Nuclear Power Plants, ser. Technical Reports Series, 1999, no. 387.

[52] A. H. Khan, Z. H. Khan, and Z. Weiguo, Model-Based Verification and Validation of Safety-Critical Embedded Real-Time Systems: Formation and Tools. Berlin, Heidelberg: Springer Berlin Heidelberg, 2014, pp. $153-183$.

[53] T. Erkkinen and M. Conrad, "Verification, validation, and test with model-based design," SAE Technical Paper, vol. 2008-01-2709, 2008.

[54] D. S. Naidu, Optimal control systems. CRC press, 2002.

[55] Verification and Validation of Software Related to Nuclear Power Plant Instrumentation and Control, ser. Technical Reports Series, 1999, no. 384.

[56] Westinghouse Technology Course R-104P Manual. USNRC Technical Training Center, 2012. [Online]. Available: https://www.nrc.gov/docs/ML0230/

[57] A. H. Harvey, Thermodynamic Properties of Water: Tabulation from the IAPWS Formulation 1995 for the Thermodynamic Properties of Ordinary Water Substance for General and Scientific Use. NISTIR, 1998. [Online]. Available: https://www.nist.gov/srd/nistir-5078 